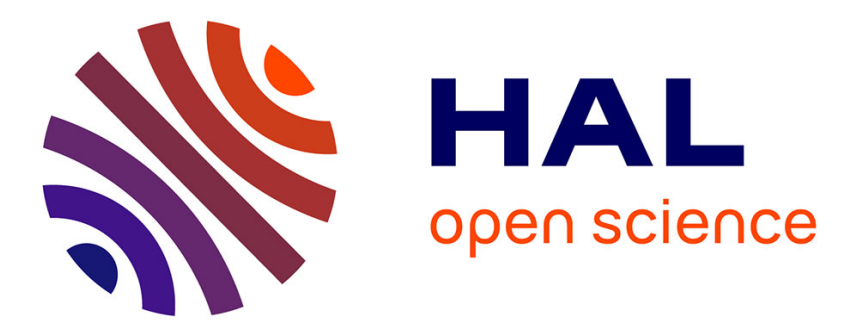

\title{
Laosuchus naga gen. nov. sp. nov., a new chroniosuchian from Southeast Asia (Laos) with internal structures revealed by micro-CT scan and discussion of its palaeobiology
}

Thomas Arbez, Christian A Sidor, J.-Sébastien Steyer

\section{To cite this version:}

Thomas Arbez, Christian A Sidor, J.-Sébastien Steyer. Laosuchus naga gen. nov. sp. nov., a new chroniosuchian from Southeast Asia (Laos) with internal structures revealed by microCT scan and discussion of its palaeobiology. Journal of Systematic Palaeontology, In press, 10.1080/14772019.2018.1504827 . hal-02048152

\section{HAL Id: hal-02048152 \\ https://hal.sorbonne-universite.fr/hal-02048152}

Submitted on 25 Feb 2019

HAL is a multi-disciplinary open access archive for the deposit and dissemination of scientific research documents, whether they are published or not. The documents may come from teaching and research institutions in France or abroad, or from public or private research centers.
L'archive ouverte pluridisciplinaire HAL, est destinée au dépôt et à la diffusion de documents scientifiques de niveau recherche, publiés ou non, émanant des établissements d'enseignement et de recherche français ou étrangers, des laboratoires publics ou privés. 
Laosuchus naga gen. nov. sp. nov., a new chroniosuchian from Southeast Asia (Laos) with internal structures revealed by micro-CT scan and discussion of its palaeobiology.

\author{
Thomas Arbez $^{*}$, Christian A. Sidor ${ }^{2}$ \& J.-Sébastien Steyer ${ }^{1}$ \\ ${ }^{1}$ Centre de Recherches en Paléontologie de Paris, UMR 7207 CNRS-MNHN-UPMC, \\ Muséum national d'Histoire naturelle, CP 38, 8 rue Buffon, 75005 Paris, France \\ ${ }^{2}$ Burke Museum and Department of Biology, University of Washington, Seattle, Washington \\ 98195, U.S.A. \\ *thomas.arbez@edu.mnhn.fr
}

\begin{abstract}
KEYWORDS: braincase - Reptiliomorpha - sensory system - palaeobiogeography phylogeny - tomography
\end{abstract}

\begin{abstract}
Chroniosuchians were a clade of non-amniotic tetrapods known from the Guadalupian (middle Permian) to Late Triassic, mainly from Russia and China. The rarity of complete or articulated remains means that relatively little is known about this group in terms of its anatomy, palaeobiology, or evolutionary history. Based on a nearly complete skull with a left hemimandible, we describe the first chroniosuchian from Laos from rocks preserving the Permian-Triassic boundary in the Luang Prabang Basin, which is located on the tectonic Indochina Block. This specimen is referred to a new genus and species, Laosuchus naga, based on numerous diagnostic features, including an extremely reduced pineal foramen; absence of palatal dentition; well-developed transverse flange of the pterygoid that contacts the maxilla; internal crest on and above the dorsal side the palate; otic notch closed by the tabular horn and the posterior part of the squamosal, forming a continuous wall; thin and high ventromedial ridge on parasphenoid. A phylogenetic analysis of 51 characters and 25 taxa reveals a basal position for Laosuchus naga among Chroniosuchia. In addition, CT scan data reveal internal structures and provide new insights about the anatomy and palaeobiology of chroniosuchians. Laosuchus naga was likely amphibious and spent most of its time in water, rather than in terrestrial environments. As chroniosuchians are nonmarine tetrapods previously known on the North
\end{abstract}


China Block, South China Block, and Laurussia, the occurrence of Laosuchus naga on the Indochina Block supports the hypothesis of physical connections between all these tectonic plates by the time of the Permo-Triassic boundary.

\section{Introduction}

The chroniosuchians were a clade of non-amniotic tetrapods that survived the Permian Triassic mass-extinction (Shishkin et al. 2000; Buchwitz et al. 2012). They occupied fresh water environments and some species were potentially terrestrial as their system of osteoderms suggests an adaptation to terrestrial locomotion (Clack \& Klembara 2009; Buchwitz et al. 2011). Chroniosuchians are divided in two families, the Bystrowianidae and the Chroniosuchidae, but both share a similar geographic range. The Bystrowianidae is the more recent of the two families, with Triassic taxa, although most of these are mainly known from fragmentary and/or disarticulated material. They present a weakly fenestrated skull (e.g. absence of preorbital fenestrae), narrow osteoderms ventrally fused with the neural spine, and ball-shaped intercentra (Novikov et al. 2000). In the other side, the Chroniosuchidae are represented by mainly Permian taxa and present elongated preorbital fenestrae, long slit-like choanae, and larger osteoderms (Novikov et al. 2000). Phylogenetically important variability occurs in the shape of their intercentra, which could be disc-, horseshoe- or ball-shaped. This variability would explain why this Chroniosuchidae does not always form a monophyletic group according to the phylogenetic analyses of Buchwitz et al. (2012).

The first chroniosuchian was discovered in 1929: it consists of ribs and osteoderms from the upper Permian of the Russian fore-Ural region and was first attributed to the seymouriamorph Kotlassia prima by Hartmann-Weinberg (1935). Later, Vjushkov (1957a, b) recognized chroniosuchians as a distinct group (Buchwitz et al. 2012). The clade Chroniosuchia was erected by Tatarinov (1972) who classified them among anthracosaurs (=Anthracosauromorpha sensu Ivachnenko \& Tverdochlebova, 1980), but a recent study placed them among stemamniotes, close to lepospondyls and diadectomorphs (Schoch et al. 2010). However, according to Clack \& Klembara (2009), who included Chroniosaurus dongusensis in their phylogenetic analysis, Chroniosuchia forms a polytomy with Silvanerpeton miripedes, Embolomeri and another clade comprising Seymouriamorpha, Gephyrostegidae, Lepospondyli and the amniote Paleothyris acadiana. Currently, 22 valid species of chroniosuchians are recognized, known from 1) the middle Permian to Middle Triassic of the Russian fore-Ural region (Novikov et al. 
2000; Buchwitz et al. 2012), 2) the middle to upper Permian of China (e.g., Young 1979; Li \& Cheng 1999; Jiang et al., 2017), 3) the Middle Triassic of Germany (Witzmann et al. 2008), and 4) the Middle or Upper Triassic of Kyrgyzstan (Schoch et al. 2010). Because of the poor preservation of the material (mostly consisting in disarticulated specimens such as isolated osteoderms), the group is poorly known in terms of its general anatomy, phylogeny, and palaeobiology (Clack \& Klembara 2009). This is especially true for the Bystrowianidae.

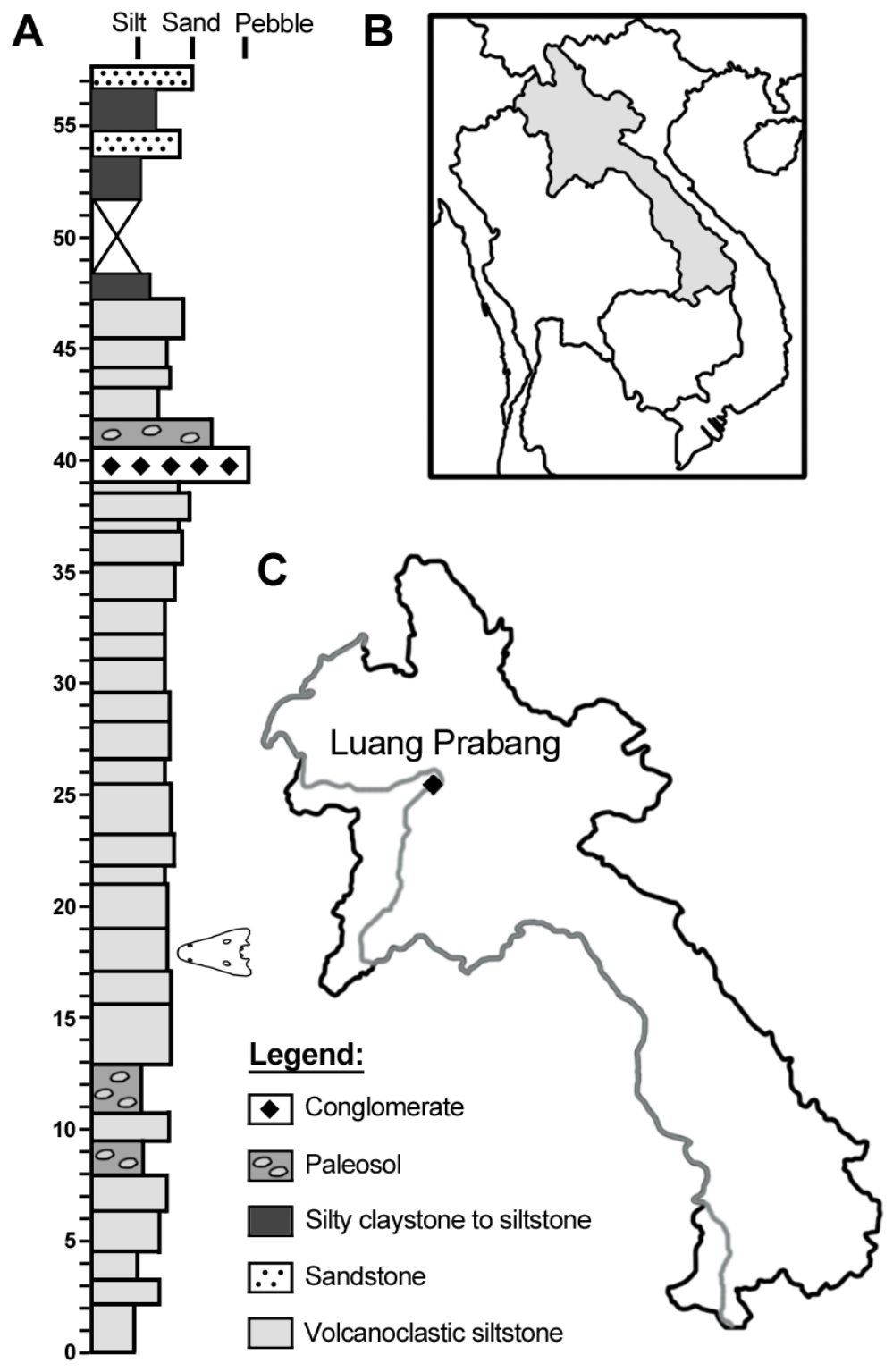

Figure 1. Geographical and geological context of Luang Prabang Basin. A. Sedimentary log from "Tan South" Section (after Bercovici et al. 2012; see their Table 1 for more details about lithofacies), scale in meters; B. Map of Southeast Asia; C. Map of Laos with the Mekong River in grey.
Here we describe a new genus and species of chroniosuchian based on a nearly complete skull from rocks preserving the PermoTriassic boundary of the Luang Prabang Basin of Laos (Fig. 1). This specimen consists of one of the best preserved chroniosuchian skulls and represents the first fossil amphibian discovered in Laos and only the second species of terrestrial vertebrate after an unidentified dicynodont (Counillon 1896; Battail et al. 1995; Battail 2009; Steyer 2009; Olivier et al. submitted). The discovery of a chroniosuchian in Laos reveals an unexpected geographic extension of the group in southeastern Pangea, and provides new insights about chroniosuchian palaeobiology and palaeoecology.

Institutional Abbreviations MDS, Musée des Dinosaures de Savannaketh, Laos 


\section{Anatomical Abbreviations}

aa: articular area; adf: adductor fossa; af: ascending flange of the pterygoid; ang: angular; bi/oci: brain or otic capsule imprint; br: basicranial recess; bo: basioccipital; ch: choane; cp: cultriforme process of the parasphenoid; d: dentary; dc: dermosensory canal; dfp: descending flange of the pterygoid; dfs: descending flange of the squamosal; ect: ectopterygoid; exo: exoccipital; gf: glenoid fossa; hm: hemimandible; ic: internal crest; iw: internal wall of the pterygoid; ju: jugal; max: maxilla; mc: medial crest of the parasphenoid; mf: Meckelian fenestra; mp: muscular pocket; n: naris; o: orbit; op: opisthotic; oea : otic exposure area; opi, opisthotic imprint; pal: palatine; pap: paroccipital process; pdp: parasymphysal dental plate; pf: pineal foramen; pmx: premaxilla; pmxf: premaxillar fontanelle; po: postorbital; pp: postparietaux; prf: prefrontal; ps: parasphenoid; pt: pterygoid; psp: postplenial; pvw: palatine vertical wall; qc: quadrate condyle; sa: surangular; so: supraoccipital; sq: squamosal; sw: subtemporal window; tab: tabular; t: tooth; tp: transverse process of the pterygoid; vo: vomer

\section{Systematic palaeontology}

Superclass Tetrapoda Goodrich, 1930

Order Reptiliomorpha Säve-Soderbergh, 1934 (sensu Benton, 2004)

Suborder Chroniosuchia Tatarinov, 1972 (sensu Witzmann \& Schoch, 2017)

Family incertae sedis

Genus Laosuchus gen. nov.

This published work and the nomenclatural acts it contains have been registered with Zoobank:

Etymology: from the country of origin (Laos) and the ancient greek soûkhos, "crocodile" for its crocodilian-like appearance.

Diagnosis: as for the species

\section{Laosuchus naga sp. nov.}

This published work and the nomenclatural acts it contains have been registered with Zoobank:

Holotype: MDS-LPQ 2005-09, a nearly complete skull (260 mm of maximum length, $160 \mathrm{~mm}$ of maximum width and $85 \mathrm{~mm}$ high) with its left hemi-mandible partly articulated. 
Etymology: from the mythological monster "Naga" (or Phaya Naga) believed to live in the Mekong River, which is close to the type locality.

Type locality: Ban Houaytan District, right bank of the Mekong River, Luang Prabang Province, northern Laos (GPS coordinates available to qualified researchers).

Type horizon: Reddish volcaniclastic siltstone with a maximum age of $251.0 \pm 1.4 \mathrm{My}$ according to $\mathrm{U}-\mathrm{Pb}$ dating of detrital zircons (Rossignol et al. 2016), Tan South section (Bercovici et al. 2012), Purple Claystones Formation (“Zone des Argiles violettes" sensu Counillon, 1896, see also Steyer, 2009).

Diagnosis: Laosuchus naga has the following autapomorphies: (1) pineal foramen extremely reduced (1 mm of diameter); (2) absence of palatal dentition (no tusks, dental rows or dental alveoli); (3) well-developed transverse flange of the pterygoid that contacts the maxilla; (4) internal crest on and above the dorsal side the palate (vomer, ectopterygoid and pterygoid); (5) otic notch closed by the tabular horn and the posterior part of the squamosal, forming a continuous wall; (6) thin and high ventro-medial ridge on parasphenoid.

Diagnostic characters, but not exclusive to Laosuchus naga: (1) absence of paired preorbital fenestrae; (2) presence of a premaxillary fontanelle; (3) maxilla and quadratojugal separated by jugal; (4) absence of anterior palatal vacuity; (5) pterygoid with transverse process and descending flange; (6) jaw with parasymphyseal dental plate.

Characters supporting an assignment to Reptiliomorpha (according to Benton, 2004 and character states in our phylogenetic analysis, see below): (1) parietal and tabular sharing a narrow suture (angustitabular condition); (2) premaxillae less than half of the skull width (Benton, 2004); (3) vomers strut-like, narrow.

Characters supporting an assignment to Chroniosuchia (according to the character states in our phylogenetic analysis and anatomical comparisons, see below for details and discussion): (1) skull roof with elaborate system of oblique transverse and sagittal ridge; (2) presence of premaxillary fontanelle; (3) prefrontal and jugal in contact anterior to orbit; (4) pterygoid flange well developed; (5) very narrow parasphenoid with a crest between the basicranial joint; (6) braincase poorly ossified. 


\section{Description}

\section{Preservation and computed tomography scan}

Overall, the specimen is well preserved, except for its left side, which is partially crushed and weathered. In addition, it was slightly compressed dorsoventrally during fossilization, which has deformed the interorbital part of the skull roof. The left hemimandible is also well preserved and found in natural articulation. There is only a little displacement of the left hemimandible towards the right side, likely due to the compression, and its lateral surface is partly weathered, especially the posterior part.

To supplement the visible external anatomy, the holotype was scanned at the AST-RX facility of the MNHN with the following parameters: microfocus beam $240 \mathrm{kV}$; voltage $210 \mathrm{kV}$; current $410 \mu \mathrm{A}$; voxel size $0.09464315 \mathrm{~mm}$; and slices resolution 1790 x 2024 pixels. 3157 virtual slices, reconstructed using GE Sensing \& Inspection Technologies Phoenix|x-ray datos|x rec, were cropped to $1251 \times 2014$ pixels to render the data more manageable and imported in the 3D reconstruction software Mimics 17.0 and 18.0 (Materialise, Leuven, Belgium). The 3D model, performed by segmentation using the "thresholding" function with grayscale from 50 to 255, was produced with the same voxel resolution and with a "Smooth Factor" of 1.0 and five iterations, in order to reduce surface irregularities due to manual segmentation. Data produced by segmentation were exported in the software 3matic 9.0 for PDF 3D creation (see in Supplementary Information).

\section{General features}

In dorsal view, the skull is subtriangular (260 mm length, $170 \mathrm{~mm}$ width and $85 \mathrm{~mm}$ height) with an elongated snout (antorbital length $165 \mathrm{~mm}$; postorbital length $80 \mathrm{~mm}$ ) whose tip is rounded (Fig. 2). The skull roof is pierced by a subtriangular premaxilla fontanelle, rounded naris and elevated oval orbits. Most of the cranial sutures are not visible because they are covered by the strong degree of ornamentation (Fig. 2). A system of ridges runs along the skull roof, and the pineal foramen is nearly indistinct (1 $\mathrm{mm}$ diameter), which is unique in chroniosuchians. The dentition is composed of conical teeth on the hemimandible, premaxillae, and maxillae in addition to numerous denticles on the palate (see below). The palate is mostly flat, especially in its anterior region. However, its posterior region shows a high vertical flange of the pterygoid. The palate is pierced by large and elongated choanae and presents subrectangular adductor fossae. 

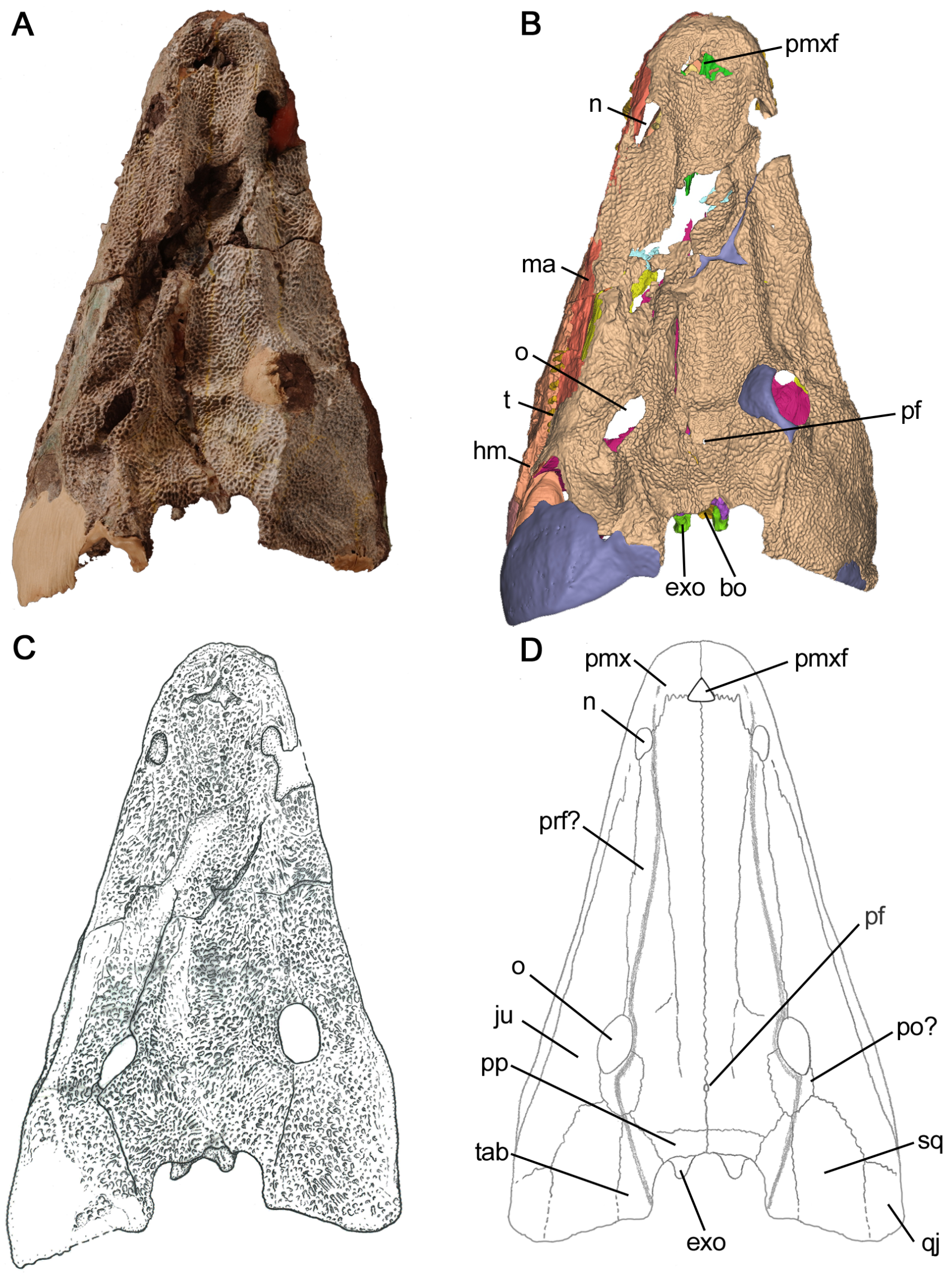

Figure 2. Laosuchus naga gen. et sp. nov. (specimen MDS-LPQ 2005-09) from the Permian/Triassic boundary of Laos in dorsal view. A. specimen photograph; B. 3D model produced with Mimics ${ }^{\circledR}$; C. anatomical drawing; D. interpretive drawing. Scale bar $=100 \mathrm{~mm}$ 


\section{Skull roof (Fig. 2, 3)}

The skull roof of Laosuchus naga shows dermal ornamentation consisting of pits and ridges of around $1 \mathrm{~mm}$ height, with a honeycomb pattern [C2(1)] (i.e., character 2, state 1). This highly pronounced ornamentation obscures most sutures and suggests an adult stage for the specimen (e.g. Steyer 2000). Dermosensory canals are visible inside the dermatocranial bones, but not on their surface (see below) [C1(2)]. This skull roof also shows paired parasagittal and oblique ridges of 3-10 $\mathrm{mm}$ in height [C3(1)]: the parasagittal ridges are straight and run from the tabular, along the medial border of the orbits and naris, to the anterior tip of the snout. The oblique ridges are straight and run from the anterior border of the orbit to the lateral border of the skull at around mid-length between the orbit and the naris.

On the left side, the external naris is ovoid (13-16 mm length, 12-14 mm width) [C5(0)] and slightly enlarged anteriorly, as is the case in Madygenerpeton pustulatus (Schoch et al. 2010). By contrast, Chroniosaurus dongusensis (Clack \& Klembara 2009) and Chroniosuchus paradoxus (Novikov et al. 2000) have a slit-like naris. The nares are well separated and lateralized with an elevated medial margin framed by the anterior ends of the sagittal ridges. Well separated and lateralized external nares are found in chroniosuchians (when preserved), except Bystrowiella schumanni where nares are close together and located almost at the tip of the snout (Witzmann \& Schoch, 2017). A subtriangular premaxillary fontanelle (18 mm length, $10 \mathrm{~mm}$ width) is present between the premaxillae [C4(1)], and represents a synapomorphy of Chroniosuchia, with only Madygenerpeton pustulatus (Schoch et al. 2010) lacking it. The fontanelle covers almost half of the interpremaxillary suture. The premaxillae are elongated, with a lateral area contacting the naris, and form the anterior end of the snout. Contrary to Bystrowiella schumanni, no lateral crest and edentulous part lateral to the choanae have been found (Witzmann \& Schoch, 2017).

The orbits are slightly oval (28 mm length, $25 \mathrm{~mm}$ height) and raised well above the skull roof, as in Madygenerpeton pustulatus (Schoch et al. 2010). However, in Laosuchus naga the orbits are proportionally smaller than those of Madygenerpeton pustulatus (Schoch et al. 2010), Chroniosaurus dongusensis (Clack \& Klembara 2009) or Chroniosuchus paradoxus (Novikov et al. 2000) (the ratio orbit length/skull length is 0.11 compared to $0.14,0.14$ and 0.18 , respectively). The prefrontal-jugal suture seems to emerge from the anterior border of the orbits. Posterior to the right orbit, a rounded bone is visible; which we interpret as the postorbital (or possibly the postfrontal). 
A
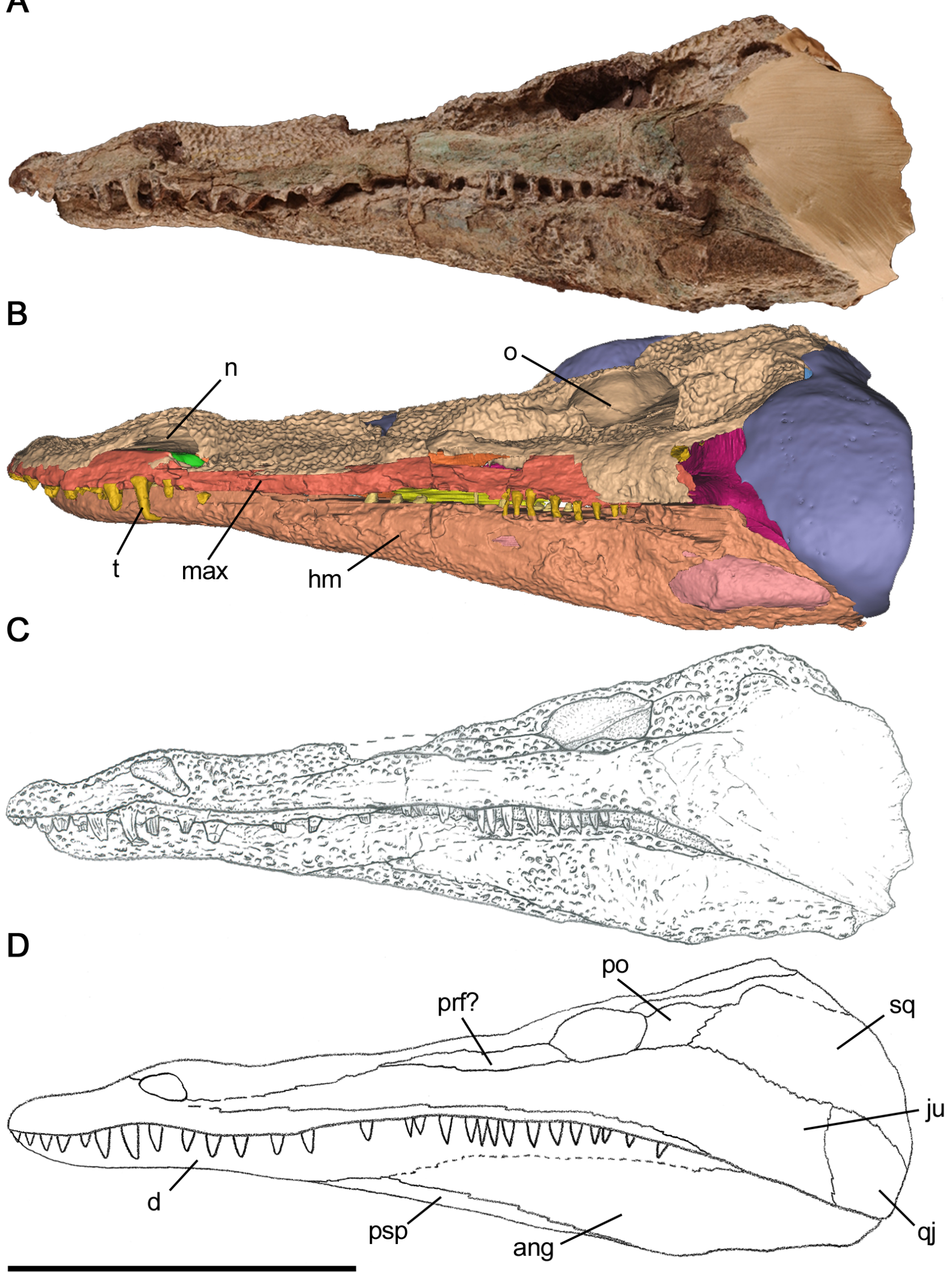

Figure 3. Laosuchus naga gen. et sp. nov. (specimen MDS-LPQ 2005-09) from the Permian/Triassic boundary of Laos in left lateral view. A. specimen photograph; B. 3D model produced with Mimics ${ }^{\circledR}$; C. anatomical drawing; D. interpretive drawing. Scale bar $=100 \mathrm{~mm}$ 
The parietal foramen is circular and extremely small (slightly less than $1 \mathrm{~mm}$ in diameter). Its size is conspicuously smaller than in other chroniosuchians (e.g., around $2.5 \mathrm{~mm}$ in Chroniosaurus dongusensis (Clack \& Klembara 2009), $2 \mathrm{~mm}$ in Madygenerpeton pustulatus (Schoch et al. 2010), $3.5 \mathrm{~mm}$ in Bystrowiella schumanni (Witzmann \& Schoch 2017) for a skull length around $61 \mathrm{~mm}, 100 \mathrm{~mm}, 84 \mathrm{~mm}$ respectively).

The postparietals are subrectangular in dorsal view (11 mm length, $21 \mathrm{~mm}$ width), heavily ornamented and partly extend on the occiput (see below). They do not present a posterior articulation surface, free of dermal sculpture, for the first osteoderm as in Bystrowiella schumanni (Witzmann \& Schoch 2017). In dorsal view, they delimit a central embayment in the posterior margin of the skull table along with the tabulars. This central embayment forms a rectangular space (28 $\mathrm{mm}$ length, $44 \mathrm{~mm}$ width), which is narrower and more elongated than that of Chroniosuchus paradoxus (Novikov et al. 2000, fig. 4.1) and Chroniosaurus dongusensis (Tverdokhlebov et al. 2005, fig. 17) in which the embayment has a parabolic outline. Interestingly, Madygenerpeton pustulatus (Schoch et al. 2010) shows two small and rounded embayments between the postparietal and the tabulars.

In Laosuchus naga, the tabulars are subrectangular (50 mm length, $16 \mathrm{~mm}$ width) and delimit the lateral border of the central embayment. Their lateral margin is completely in contact with the squamosal, thereby eliminating any indication of a tabular horn and otic notch, a unique situation in Chroniosuchia. The tabular also lacks a ventromedial portion free of dermal sculpture as in Bystrowiella schumanni (Witzmann \& Schoch 2017).

The squamosals are subrectangular in lateral view (55 mm length, $29 \mathrm{~mm}$ width) with, as an otic notch is absent, a straight posterior margin. Apart from the lack of an otic notch, the overall shape of the squamosal is similar to Chroniosaurus dongusensis (Clack \& Klembara 2009). However, in Laosuchus naga, its sutures are unclear, and what is drawn in Figures 2 and 3 might also encompass the supratemporal.

The jugals are elongated subtriangular bones (155 mm length, $28 \mathrm{~mm}$ width) similar to Bystrowiella schumanni (Witzmann \& Schoch 2017) and Bystrowiana permira (Novikov et al. 2000). In Laosuchus naga, the jugal shows a dermal sculpture also found on the whole skull roof: this ornamentation does not present elongated ridges radiating from a centre, as mentioned for Bystrowiella schumanni (Witzmann \& Schoch, 2017) and Bystrowiana permira (Novikov et al. 2000). 
The quadratojugal is subtriangular in lateral view (21 mm length, $33 \mathrm{~mm}$ width) and relatively short compared to other chroniosuchians, as it does not reach the maxilla [C15(1)]. In Laosuchus naga the quadratojugal is clearly different from Bystrowiana permira, where the quadratojugal shows dorsal and ventral curvatures (Novikov et al. 2000).

Unfortunately, the suture between the maxilla and the premaxilla is not visible in ventral view. However, together these bones form a long and slender structure $(215 \mathrm{~mm}$ length, $5 \mathrm{~mm}$ width and $12 \mathrm{~mm}$ height): this structure is curved in its most anterior part and delimits the choanae laterally, the vomer anteriorly, and the ectopterygoid and the pterygoid posteriorly.

\section{Palate (Fig. 4, 5, 6B)}

The palate is fragmented and incompletely preserved, especially the left side. This renders the sutures between the palatal bones difficult to determine with confidence. An anterior palatal fenestra is not present in Laosuchus naga, similar to the condition in anthracosaurs like Anthracosaurus russelli (Panchen 1977) or Pholiderpeton attheyi (Panchen 1972) and the chroniosuchian Chroniosaurus dongusensis (Klembara et al. 2010). However, Laosuchus naga shows very large trapezoidal choanae (75 mm length, $20 \mathrm{~mm}$ width) with rounded posterior extremities. These openings are especially large and elongated compared to those of other chroniosuchians and anthracosaurs (the ratio between choanae length and skull length is 0.34 in Laosuchus naga compared to 0.14 for Anthracosaurus russelli, Panchen 1977; 0.14 for Proterogyrinus scheelei, Holmes 1984; 0.17 for Chroniosuchus paradoxus, Novikov et al. 2000 and 0.16 for Chroniosaurus donguensis, Klembara et al. 2010).

In ventral view, the vomer is rectangular and elongated (60 mm length, $20 \mathrm{~mm}$ width). It thickens laterally and medially, delimiting a flat central depression. The anterior margin of the vomer is convex ventrally. Its lateral margin is concave and borders the choana, whereas its medial margin is straight. Its posterior region is not preserved.

The palatine is subrectangular (40 mm length, $25 \mathrm{~mm}$ width). Its posterior limit is not very clear. Its lateral margin, which is slightly concave, thickens dorsally to form a vertical wall that forms the lateral margin of the choana. This bony wall begins in the first one-third of the palatine's length and its height increases posteriorly and regularly up to $8 \mathrm{~mm}$. 

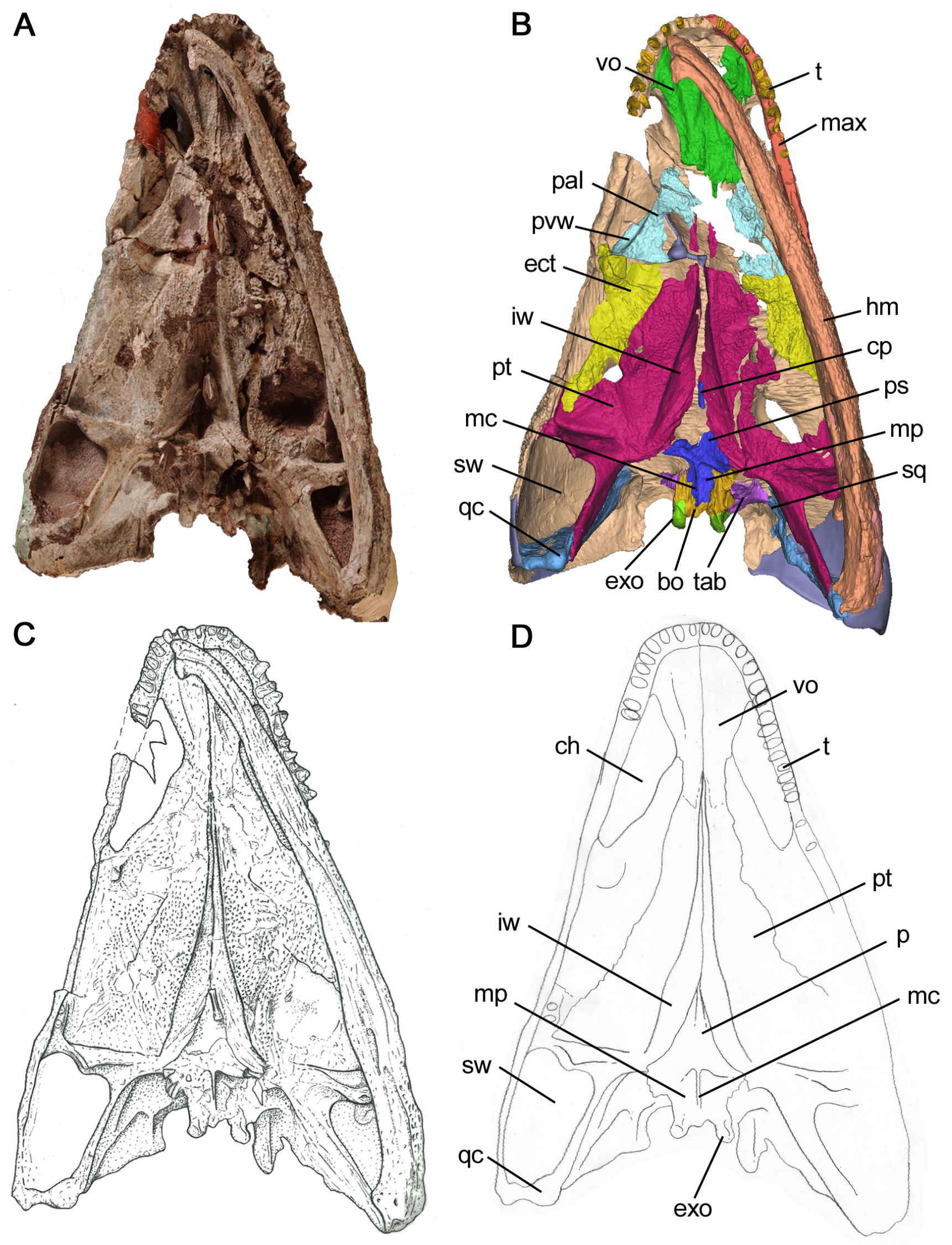

Figure 4. Laosuchus naga gen. et sp. nov. (specimen MDS-LPQ 2005-09) from the Permian/Triassic boundary of Laos in palatal view. A. specimen photograph; B. 3D model produced with Mimics ${ }^{\circledR}$; C. anatomical drawing; D. interpretive drawing. Scale bar $=100 \mathrm{~mm}$ 
The outline of the ectopterygoid forms an elongated triangle in ventral view (175 mm length, $25 \mathrm{~mm}$ width) with a posteriorly directed tip. It is proportionally wider than that of Chroniosaurus dongusensis (Klembara et al. 2010) and Chroniosuchus paradoxus (Novikov et al. 2000) and does not reach the subtemporal window. However, this bone is very fragmented and consequently its suture with the palatine remains hypothetical (as represented by a dotted line in Fig. 4D).

The pterygoid covers most of the palatal surface (150 mm length, $60 \mathrm{~mm}$ width) and consists of five parts: the horizontal palatal ramus, the internal wall, the articular area, the transverse process including the descending flange, and the quadrate ramus including the ascending flange. The right pterygoid is well preserved except in its anterior extremity, which may partly cover the vomer, as in Chroniosaurus donguensis (Klembara et al. 2010). The palatal ramus is triangular and elongated, as in Chroniosaurus donguensis (Klembara et al. 2010). Its medial margin extends dorsally and forms a broad inturned flange, called here the "internal wall", which becomes progressively more vertical anteriorly, as in Archeria crassidisca (Holmes 1989) and Chroniosaurus dongusensis (Klembara et al. 2010). The most posterior rim of the internal wall is marked by a medial groove bordered by two crests in which the parasphenoid basal plate is inserted, forming an elongated basicranial articulation. This is different from Chroniosaurus donguensis (Klembara et al. 2010) and Chroniosuchus paradoxus (Novikov et al. 2000), where a well-developed process of the pterygoid forms the basicranial articulation. The basicranial articulation of Laosuchus naga also contrasts with the common hemispherical basipterygoid process seen in various early tetrapods (e.g. Palaeoherpeton decorum, Panchen 1964; Pholiderpeton attheyi, Panchen 1972; Chroniosaurus dongusensis, Clack \& Klembara 2009; Eryops megacephalus, Sawin 1941; Edops craigi, Romer \& Witter 1942). However, it is reminiscent of the shallow basipterygoid process with an elongated articular area presenting grooves and ridges in Discosauriscus austriacus (Klembara 1997). In Laosuchus naga, the transverse process of the pterygoid projects laterally until it articulates with the medial surface of the lower jaw. This transverse process forms a thick and straight ramus with a descending flange laterally directed, making it triangular in anterior view, and similar to that of Bystrowiana permira (Novikov et al. 2000, after Ivakhnenko \& Tverdokhlebova 1980). The posterior surface of the right descending flange shows seven grooves, which may correspond to the insertion of ligaments of the musculus pterygoideus (Carroll 1969; Holmes 1989). The quadrate ramus of the pterygoid bears the ascending flange ('lamina ascendens' sensu Bystrow \& Efremov 1940), which is hooked, posteriorly directed, and with a rounded extremity contacting the quadrate. 
Dorsally, the vertical flange sutures to the descending flange ('lamina descendens' sensu Bystrow \& Efremov 1940) of the squamosal. Ventrally, the quadrate ramus is slightly thicker, and the ascending flange extends anteriorly into the posterior part of the basicranial articulation area. A recess is visible at the base of the anterior part of both ascending flanges (Fig. 5), which we interpret as the basicranial recess. This recess is similar to the basicranial recess of Kotlassia prima (Bystrow 1944) and Discosauriscus austriacus (Klembara 1997), where the internal morphology of the skull is well known. Just dorsal to this recess is a bony extension whose shape is reminiscent of the epipterygoid. However, it is unclear if this extension is the epipterygoid itself or a part of the lamina ascendens with a badly preserved basicranial recess at its base.

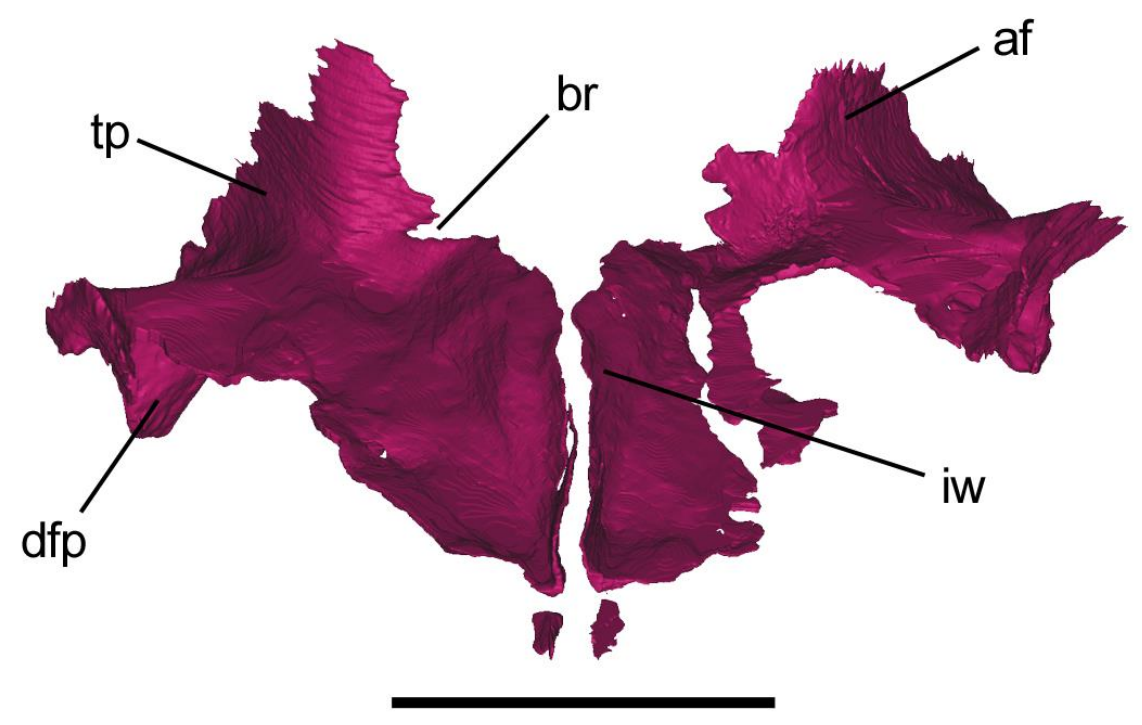

Figure 5. 3D model of left and right pterygoids in anterior view of Laosuchus naga gen. et sp. nov. (specimen MDS-LPQ 2005-09) produced with Mimics ${ }^{\circledR}$. Scale bar $=50 \mathrm{~mm}$.

The parasphenoid is known by its basal plate $(150 \mathrm{~mm}$ length, $60 \mathrm{~mm}$ width) and a small, disarticulated fragment of the cultriform process. The basal plate has a diamond shape in ventral view. Its posterior portion is subtriangular, deeper than its anterior part, as preserved, and divided by a thin and high median ridge, as in Discosauriscus austriacus (Klembara 1997, fig. 20). The crista muscularis, visible in the mid-region of the basal plate, is oriented transversely and is straight (this crest is curved in Chroniosaurus dongusensis; Klembara et al. 2010). The median ridge and the crista muscularis delimit two subtriangular muscular pockets, which are exceptionally deep in comparison with those of others stem-amniotes (e.g. Chroniosaurus dongusensis, Klembara et al. 2010; Chroniosuchus paradoxus, Novikov et al. 2000; Discosauriscus austriacus, Klembara 1997; Archeria crassidisca, Holmes 1989). 

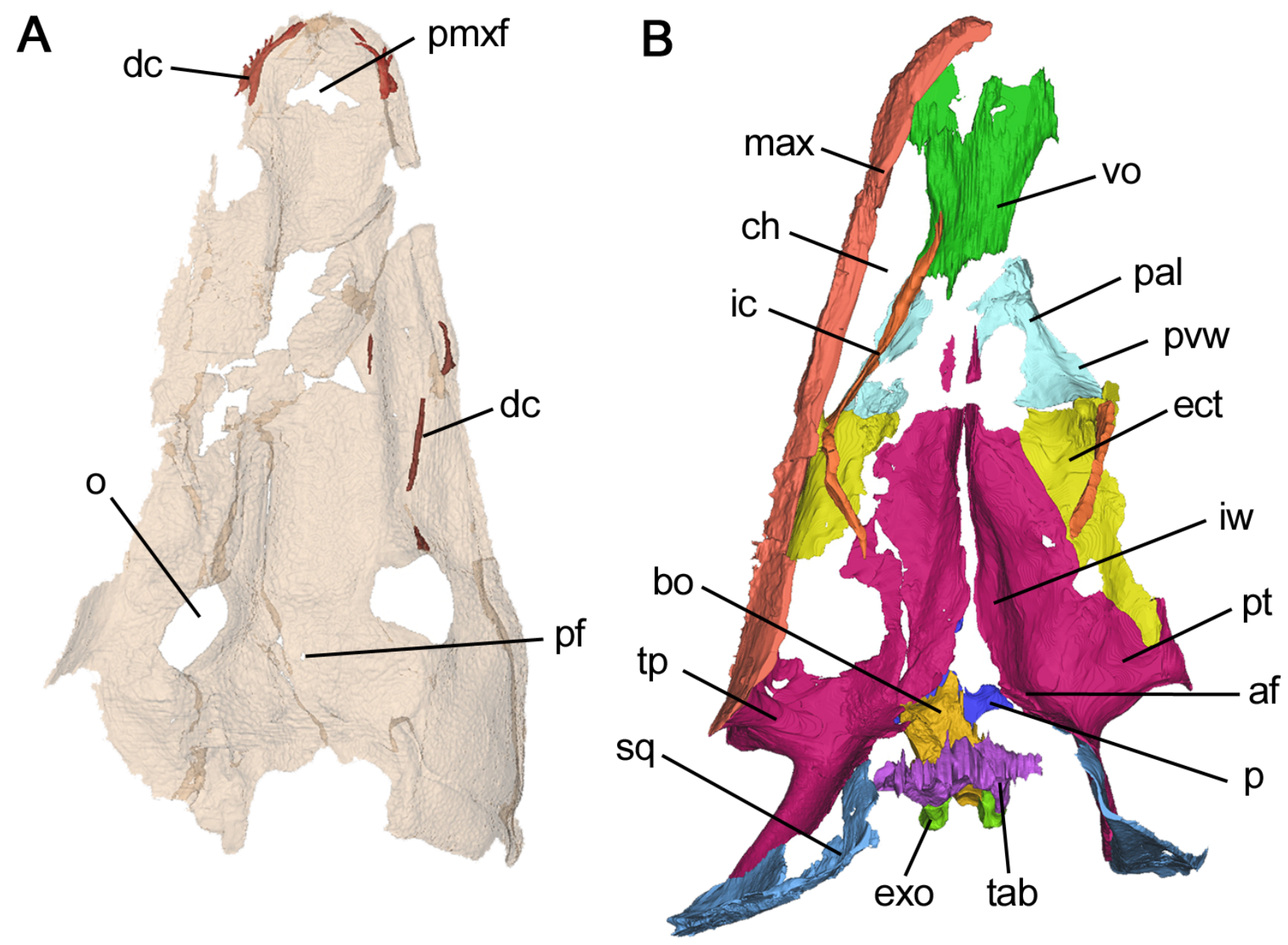

C

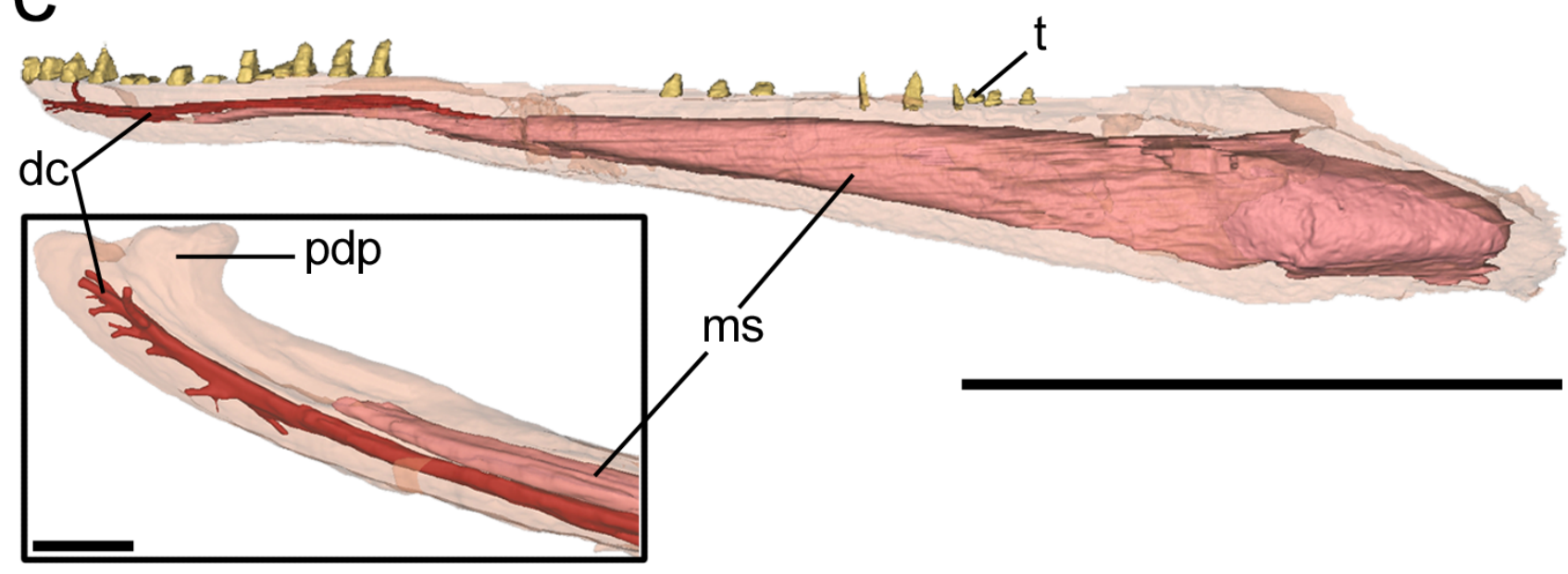

Figure 6. 3D model of the internal canal system and cranial structures of Laosuchus naga gen. et sp. nov. (specimen MDS-LPQ 2005-09) produced with Mimics ${ }^{\circledR}$. Skull roof and left hemimandible are transparent. A. dorsal view of the skull roof. Scale bar $=60 \mathrm{~mm}$; B. dorsal view with skull roof removed. Scale bar $=60 \mathrm{~mm}$; C. Lateral view of left hemimandible (scale bar $=60 \mathrm{~mm}$ ) with close up on the anterior extremity of the left hemimandible in dorsal (scale bar $=10 \mathrm{~mm}$ ). 
The vomers and the skull roof (at a location which should correspond to the nasals and premaxillae) delimit a space that presumably housed the nasal capsules. Posteriorly, the two internal walls of pterygoids delimit a longitudinal space (presumably ventrally bordered by the cultriform process) leading to the nasal capsule space. Hence, this longitudinal space likely housed the olfactory nerves. If this assumption is correct, the internal walls would have played a reinforcement role for the sphenethmoid.
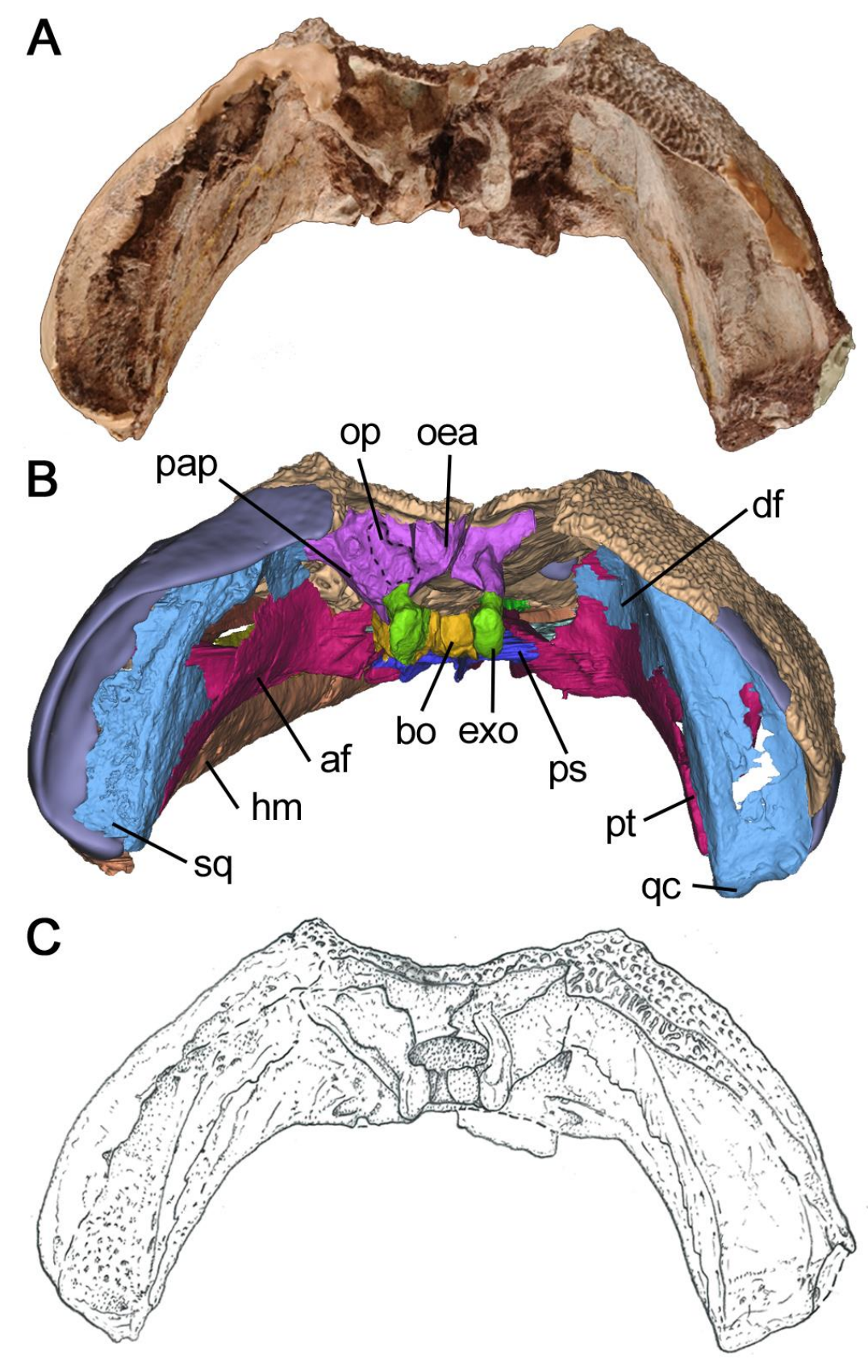

Figure 7. Laosuchus naga gen. et sp. nov. (specimen MDS-LPQ 2005-09) from the Permian/Triassic boundary of Laos in occipital view. A. specimen photograph; B. 3D model produced with Mimics $^{\circledR}$; C. anatomical drawing. Scale bar $=100 \mathrm{~mm}$ 
The subtemporal fenestrae are relatively large and subrectangular $(58 \mathrm{~mm}$ length and $38 \mathrm{~mm}$ width). Their anatomy differs from that of Chroniosaurus dongusensis (Klembara et al. 2010) and Chroniosuchus paradoxus (Novikov et al. 2000), where an anterior extension of the fenestra is found between the ectopterygoid and the maxilla.

Interestingly, CT data reveal a pair of long internal crests running along on dorsal surface of the palate (Fig. 7B). The left one is better preserved and arises from the posterolateral region of the vomer. It follows the margin of the choana and forms a vertical crest of a variable thickness on the palatine and ectopterygoid (1.5-4 mm). Posteriorly to the choana, this crest contacts the maxilla on which it turns posteromedially and overlies the ectopterygoid and pterygoid, but without making contact. It is not possible to say if this crest is formed by several palatal bones or if it consists of a single unit. Regardless, no equivalent has been found in other taxa.

\section{Occiput (Fig. 7, 8)}

The occiput of Laosuchus naga is well preserved $(160 \mathrm{~mm}$ width, $85 \mathrm{~mm}$ height and $50 \mathrm{~mm}$ depth). The foramen magnum is broadly oval in outline (18 mm width, $8 \mathrm{~mm}$ height), which is similar to other anthracosaurs where the foramen magnum is circular (e.g. Palaeoherpeton decorum, Panchen, 1964) to oval (e.g. Archeria crassidisca, Holmes 1989). Laosuchus naga is the first chroniosuchian where the foramen magnum can be described, which limits

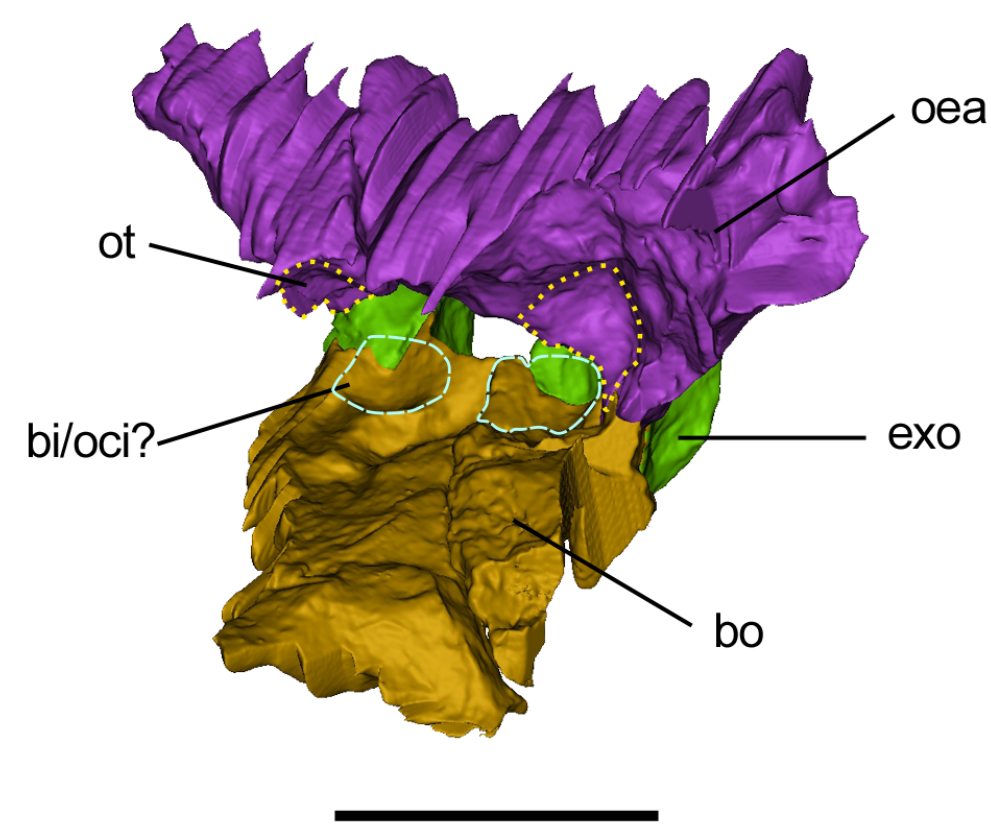

Figure 8. 3D model of the occipital area in anterolateral view of Laosuchus naga gen. et sp. nov. (specimen MDS-LPQ 2005-09) produced with Mimics ${ }^{\circledR}$. Scale bar $=20 \mathrm{~mm}$ comparisons to other chroniosuchians. The occipital condyles are broadly separated from each other and face posteriorly and slightly ventrally. They measure $17 \mathrm{~mm}$ in height and $8 \mathrm{~mm}$ in width. The exoccipitals are separated from the skull roof by an area we call the "otic exposure area" (hereafter OEA), which is formed by the tabular, postparietal, supraoccipital and opisthotic (unfortunately no sutures delimiting these bones are visible). In occipital view, the 
OEA is trapezoidal in outline. Its lateral side consists of a buttress that may be the paraoccipital process. This resembles the condition found in Embolomeri sensu Clack \& Klembara (2009). The internal side of the OEA is concave, possibly to accommodate the otic capsule (Fig. 8). Below this ventral extension of the tabular and dorsolaterally to the exoccipital column, a shallow (1-2 $\mathrm{mm}$ ) and small ovoid $(3 \times 4 \mathrm{~mm})$ depression is visible: this post-temporal depression may be homologous to the post-temporal fenestra observed in other stegocephalians, such as temnospondyls (e.g. Arbez et al., 2017).

An oblique fissure passes through the postparietals and the OEA, and reaches the foramen magnum, likely passing though the suture between the two postparietals and the synotic tectum of the supraoccipital. The left opisthotic, which is well preserved, has a bean-shape in posterior view. It is fused with the OEA and forms the paroccipital flange, a common feature observed in various early tetrapods such as Anthracosauroideae (e.g. Panchen 1977; Smithson 1985), Seymouriamorpha (e.g. Laurin 1996), Diadectomorpha (e.g. Romer 1946) and Lepospondyli (Caroll \& Gaskill 1978). As in others chroniosuchians, the sphenethmoid is not visible (even with the CT scan), reinforcing the pattern of a strong reduction of the endocranial ossification characteristic of the group (Novikov et al. 2000).

The basioccipital is reduced posteriorly, a situation similar to Gephyrostegus bohemicus (Carroll 1970) and Asaphestera intermedia (Carroll \& Gaskill 1978). In Laosuchus naga, it is limited by the space between the occipital condyles and forms a rectangular thick plate. As this basioccipital is not well developed ventrally (as is the case in anthracosaurs such as Archeria crassidisca, Holmes 1989, and Palaeoherpeton decorum, Panchen 1964), it likely did not articulate with the cervical vertebrate. Its dorsal surface is posteriorly marked by two rounded depressions (Fig. 8). As they are congruent with the concavities on the internal surface of the OEA (see above), they may correspond to the emplacement of the otic capsule.

The exoccipitals are laterally flattened and ovoid, as in Chroniosaurus dongusensis (Clack \& Klembara 2009) and Discosauriscus austriacus (Klembara 1997). They are almost reduced to forming just the occipital condyles (17 mm height and $8 \mathrm{~mm}$ width), but remain distinctly separated by the basioccipital. The foramen for cranial nerves IX - X, visible dorsally, is located on the suture between the left exoccipital and its corresponding opisthotic. The foramen for cranial nerve XII is slightly more ventral and visible on the lateral surface of the condyle. These foramina are rounded ( $1 \mathrm{~mm}$ diameter), which is similar with those of Archeria crassidisca (Clack \& Holmes 1988) and Discosauriscus austriacus (Klembara 1997). 
The quadrate is difficult to distinguish from the squamosal, and so both bones were 3D modeled as a single structure. The right quadrate shows two condyles: the medial one $(10 \mathrm{~mm}$ in anteroposterior length) is rounded, and the lateral one is much smaller. Anterolaterally, the dorsal process of the quadrate interlocks with the posterior part of the quadrate ramus of the pterygoid and extends into the subtemporal fenestra. The dorsal process has a small depression on the medial side, marking the contact with the tip of the pterygoid quadrate ramus. In ventral view, the quadrate is relatively short, as in Chroniosuchus paradoxus (Novikov et al. 2000) and Chroniosaurus dongusensis (Klembara et al. 2010). A short quadrate seems to be characteristic of chroniosuchians. However, as the quadrate is only depicted in ventral view in Chroniosuchus paradoxus (Novikov et al. 2000) and Chroniosaurus dongusensis (Klembara et al. 2010), this should be taken with caution. The quadrate of Laosuchus naga is located substantially ventral to the exoccipital condyle [C32(0)].

\section{Dentition (Fig. 9)}

The dentition of Laosuchus naga includes both marginal teeth and palatal denticles. The marginal dentition preserves 45 teeth, closely set on the premaxillae, maxillae, and dentary. Where complete, these teeth are typically conical, but certain teeth can be slightly curved posteriorly, and anteroposteriorly or laterally flattened according to their position. The tooth height is relatively constant along the jaw, as in Chroniosaurus dongusensis (Clack \& Klembara 2009) and in contrast to Bystrowiella schumanni (Witzmann \& Schoch 2017). In Laosuchus $n a g a$, this tooth height is of $9 \mathrm{~mm}$ in average (with rare extremes between 6 to $14 \mathrm{~mm}$ ). CT data suggest that the marginal teeth are labyrinthodont, with infolded enamel and a central pulp cavity (Fig. 9D), as observed also in Bystrowiella schumanni (Witzmann \& Schoch 2017).

On the palatal surface, numerous small denticles are scattered irregularly, notably on the ectopterygoids and the palatal rami of the pterygoids, as is the case in Chroniosuchus paradoxus (Novikov et al. 2000) and Chroniosaurus dongusensis (Klembara et al. 2010). Palatal tooth row or tusks (or alveoli) have not been found.

\section{Left hemimandible (Fig. 9)}

The left hemimandible is partially articulated with the skull (Figs. 3, 4). It is relatively narrow and elongate, with a slight anteromedial curvature, measuring $265 \mathrm{~mm}$ in length and 11-16 mm in width. Anteriorly, the mandible measures only $8 \mathrm{~mm}$ in height, but this measurement increases to a maximum of $28 \mathrm{~mm}$ in the region of the angular. In overall shape, the mandible of Laosuchus naga is most similar to that of Chroniosuchus paradoxus (Novikov et al. 2000). 
In Laosuchus naga, the labial surface of the hemimandible is ornamented by pits and ridges but this ornamentation is partly weathered and makes it difficult to trace the sutures in places. However, a close examination under UV light reveals thin depressions in the posterior and ventral regions of the dentary which suggests the locations of sutures with the postsplenial and angular, respectively.

CT data allow for visualization of the glenoid region of the mandible (Fig. 9), which is otherwise obscured because it is in articulation with the skull (Fig. 3). The articular presents a glenoid fossa formed by two concave ovals facets for the articulation with the quadrate condyles. The larger facet (16 mm length, $7 \mathrm{~mm}$ width) is lingually situated to the smaller one ( $8 \mathrm{~mm}$ length, $4 \mathrm{~mm}$ width). When compared to the condition seen in the anthracosaurs

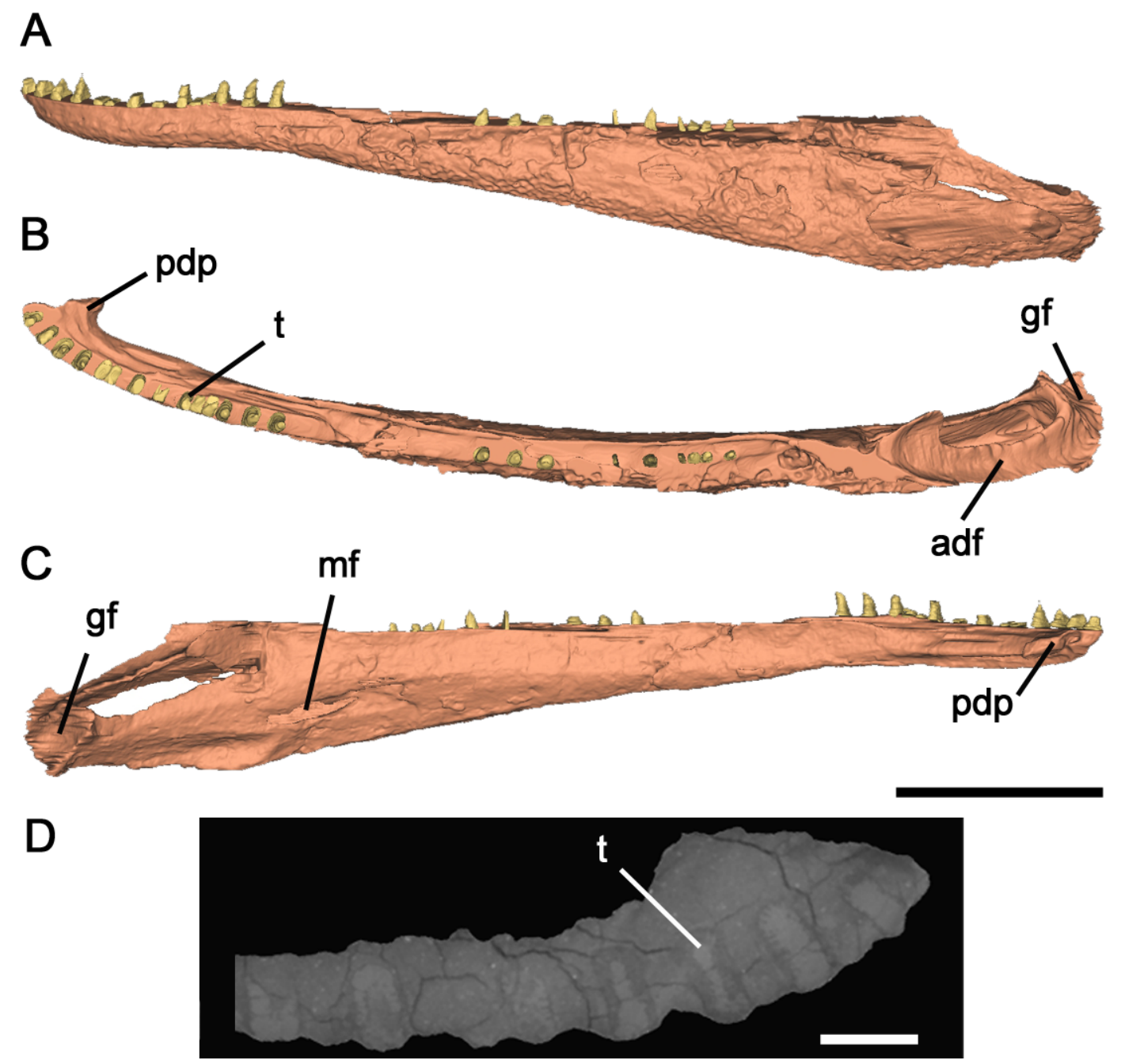

Figure 9. Left hemimandible of Laosuchus naga, gen. et sp. nov. (specimen MDSLPQ 2005-09) from the Permian/Triassic boundary of Laos. 3D model in A, labial view; $\mathrm{B}$, dorsal view; and $\mathrm{C}$, lingual view. Scale bar $=50 \mathrm{~mm}$; D. tomography of the anterior extremity of the left mandible. Scale bar $=5 \mathrm{~mm}$ 
Pholiderpeton attheyi (Panchen 1972), Proterogyrinus scheelei (Holmes 1984), and Archeria crassidisca (Holmes 1989), the jaw articulation in Laosuchus naga is positioned relatively ventrally. In Laosuchus naga, the adductor fossa (58 $\mathrm{mm}$ length, $17 \mathrm{~mm}$ width) is located on the posterior one-quarter of the mandible and has a relatively low lateral margin, nearly reaching the height of its medial margin. This organization contrasts with Chroniosuchus paradoxus, where the medial margin is well below the lateral one (Novikov et al. 2000), and with the condition in anthracosaurs in general (e.g. Pholiderpeton attheyi, Panchen 1972; Proterogyrinus scheelei, Holmes 1984 and Archeria crassidisca, Holmes 1989). At the anterior limit of the adductor fossa, a bony extension ( $15 \mathrm{~mm}$ length) is posterodorsally directed but this could be due to the deformation of the specimen. The lingual side of the mandible presents a shallow and elongate Meckelian fenestra (24 mm length, $6 \mathrm{~mm}$ height), but its reduced height could be related to the overall flattening of the specimen. The Meckelian fenestra is unique as reported in Chroniosaurus dongusensis (Clack \& Klembara, 2009) and Bystrowiella schumanni (Witzmann \& Schoch, 2017). On the lingual side of the hemimandible, an elongated depression (48 $\mathrm{mm}$ length, $10 \mathrm{~mm}$ height) is present posteroventrally, likely for the attachment of jaw adductor musculature.

The parasymphyseal dental plate is visible in dorsal view: this small and hook-shaped extension of the dentary (26 mm length, $10 \mathrm{~mm}$ of maximum width) is posteriorly directed but does not bear teeth or tusks, as is the case in many stegocephalian taxa (e.g., Ichthyostega stensioei, Jarvik, 1996; Archeria crassidisca, Holmes 1989; Watsonisuchus madagascariensis, Steyer 2003).

\section{Dermo-sensory and/or nutritive canals (Fig. 6)}

Thanks to the CT-scan, dermo-sensory and/or nutritive canals were observed within the premaxilla, maxilla, prefrontal, jugal, and dentary. The premaxillary canal is well developed: it corresponds to a large primary canal (1-3 $\mathrm{mm}$ in diameter) which ramifies into smaller secondarily canaliculi (of sub-millimeter diameter) connected to the surface of the bone by tiny foramina. Interestingly, such foramina are also found in Bystrowiella schumanni (Witzmann \& Schoch 2017). The dentary canal is also well developed and ramified: its primary canal separates from the Meckelian space to follow it in the anterior direction, then it bifurcates anteriorly in secondarily straight canaliculi also emerging and reaching the lateral surface of the hemimandible. These internal canals may result from an internalization of the lateral-line system, as noted in other chroniosuchians (Clack \& Klembara 2009; Golubev 1998). Their possible function is discussed below. 


\section{Phylogeny (Fig. 10)}

In order to determine the phylogenetic position of Laosuchus naga among early tetrapods, we conducted a phylogenetic analysis. The recent and most exhaustive phylogenies dealing with early tetrapods including reptiliomorphs are those of Schoch et al. (2010), Buchwitz et al. (2012), and Witzmann \& Schoch (2017), which take into account 5, 12 and 2 chroniosuchian taxa respectively. As the matrix of Schoch et al. (2010) also contains the largest proportion of cranial characters compared with postcranial ones (i.e. $65.4 \%$, contra 48.6 and $35.3 \%$ for the matrices of Buchwitz et al. (2012) and Witzmann \& Schoch (2017) respectively), it is believed to be the most relevant dataset here to test the relationships of Laosuchus naga within chroniosuchians.

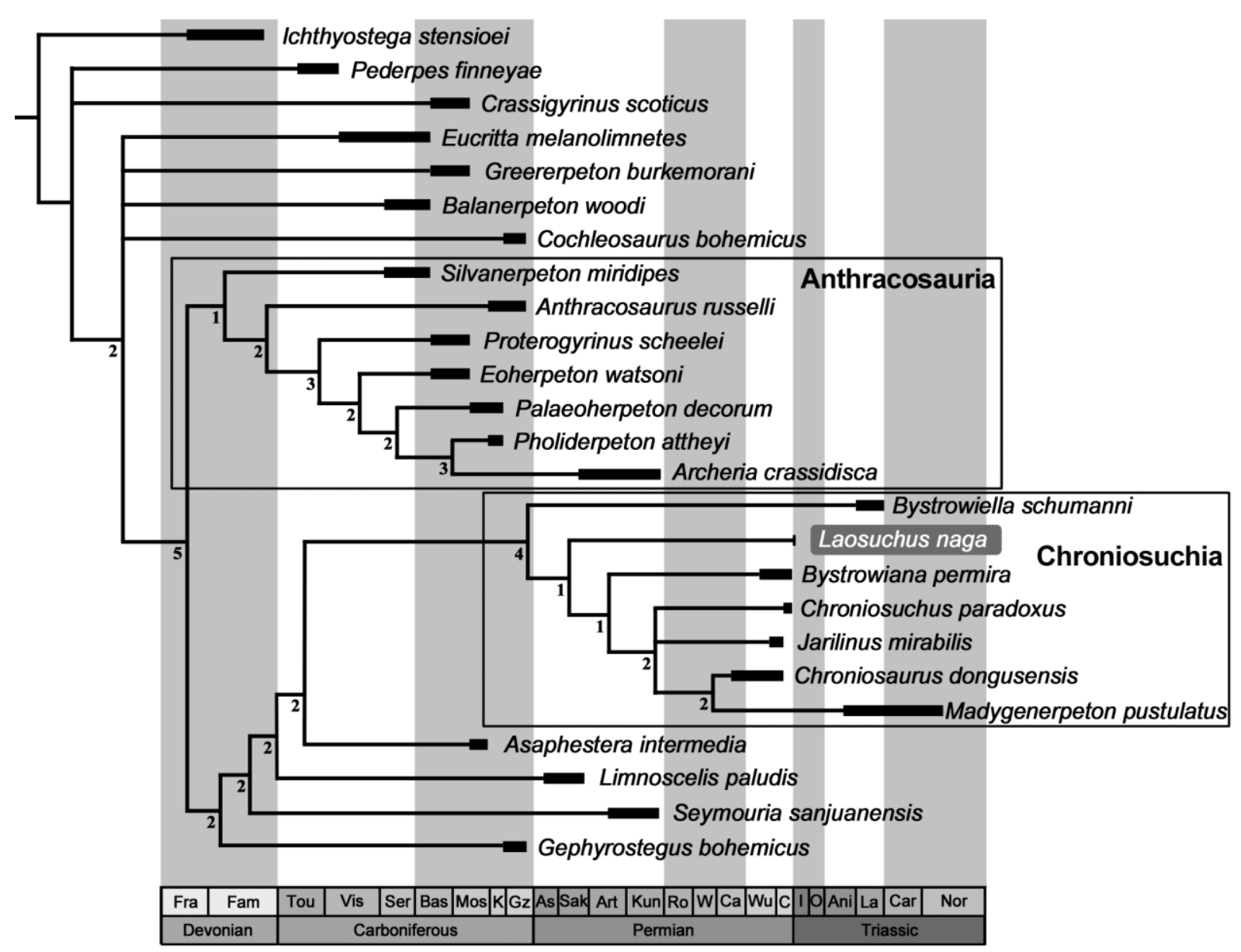

Figure 10. Phylogenetic position of Laosuchus naga mapped on a stratigraphic scale. Strict consensus $(\mathrm{L}=139$ steps; $\mathrm{CI}=0.417$; $\mathrm{RI}=0.645)$ of 18 MPTs based on 25 taxa and 51 characters. Black numbers represent Bremer Index. 
To potentially reinforce the results of using the matrix of Schoch et al. (2010) in our phylogenetic analysis, we also tested a preliminary analysis using the matrix of Buchwitz et al. (2012), adding Laosuchus naga and Bystrowiella schumanni (Witzmann \& Schoch 2017), and using the heuristic search algorithm and ACCTRAN optimization of PAUP 4.0 (Swofford 2003): we obtained 416 most parsimonious trees (MPTs) of 158 steps (CI =0.519; RI =0.759), the strict consensus of which (see Supplementary Information) placed Laosuchus naga as sistertaxa to Madygenerpeton pustulatus (Schoch et al. 2010) but based on optimization of missing characters mostly. Moreover, on nine characters supporting the monophyly of Chroniosuchidae (six based on osteoderms, three based on skull), only one unambiguous symplesiomorphic character is coded in Laosuchus naga (quadrates well posterior to condyles, C55(0) in Buchwitz et al. 2012); and on eight characters supporting the monophyly of Bystrowianidae (five based on osteoderms, three based on skull), only one ambiguous synapomorphic character is found in Laosuchus naga (premaxilla short and blunt, C29(1) in Buchwitz et al. 2012). For these reasons, we found the matrix of Buchwitz et al. (2012) not useful for determining the systematic position of Laosuchus naga.

We therefore used the matrix of Schoch et al. (2010) by adding Laosuchus naga and Bystrowiella schumanni (Witzmann \& Schoch 2017), by combining their previous characters 1 and 2 (into our current character 1), and by recoding 28 character states (see Supplementary Information). We also used the name of the only microsaur Asaphestera instead of 'microsauria' as Schoch et al. (2010) did. The slightly modified matrix contains 25 taxa and 51 characters (see Supplementary Information) and was analysed by the branch and bound algorithm and ACCTRAN optimization of PAUP 4.0, with all the character states unordered (except for numbers 35 and 48 because they correspond to a morphological transformation series) and equally weighted. We used Ichthyostega stensioei (Jarvik 1996) as the outgroup. These parameters correspond to those of Schoch et al. (2010).

Our analysis resulted in 18 MPTs of 130 steps $(C I=0.446$; $\mathrm{RI}=0.692)$, the strict consensus of which is shown in Figure 10. Our results are mostly congruent with those of Clack \& Klembara (2009), Schoch et al. (2010) and Witzmann \& Schoch (2017), as anthracosaurians (including Silvanerpeton or not) and chroniosuchians form two distinct clades. Compared with Schoch et al. (2010), our results are almost the same except for the position of Greererpeton (which forms a polytomy with Eucritta, Balanerpeton, Cochleosaurus and the stem-amniote clade here), Silvanerpeton (which is here a stem-anthracosaur), and Jarilinus (which may not be strictly related to Chroniosuchus, as both form a polytomy with other chroniosuchians). 
Laosuchus naga and Bystrowiella schumanni fall at the base of the chroniosuchian clade (Fig. 10), with which they share the following synapomorphies: Unequivocal C7(1); C35(2); C36(1); C48(1); Equivocal C51(1); and the following symplesiomorphies: Unequivocal C14(1); Equivocal C33(0); C42(0). The assignment of Laosuchus naga to Chroniosuchia is also supported by a strong Bremer index of 4 . Within chroniosuchians, Laosuchus naga is sistertaxon to the clade (Bystrowiana (Chroniosuchus, Jarilinus (Chroniosaurus, Madygenerpeton))).

\section{Discussion}

\section{Taxonomic assignment}

The assignment of Laosuchus naga to Chroniosuchia could be questionable if the definition of the clade by Witzmann \& Schoch (2017) was strictly followed. Indeed, Laosuchus naga is unfortunately not represented by vertebrae or osteoderms which bear typical characters diagnosing the clade Chroniosuchia (Witzmann \& Schoch, 2017). However, in our phylogenetic analysis, of the nine character states to be found supporting the clade Chroniosuchia [C7(1); C14(1); C33(0); C35(2); C36(1); C42(0); C48(1), C51(1)], three are known in Laosuchus naga [C14(1); C33(0); C51(1)]. Moreover, although none of the following anatomical features are exclusive to Chroniosuchia, their combination is characteristic and strengthens the attribution of Laosuchus naga to Chroniosuchia: 1, elaborated system of oblique, transverse, and sagittal ridges; 2, absence of external sulci; 3, elongated choanae; 4, well-developed transverse process of pterygoid; 5, internal flange of pterygoid; 6 , extremely thin cultriform process of the parasphenoid; 7, thin quadrate (in ventral view); 8 , strong reduction of the braincase ossification; 9, single Meckelian fenestra; 10, low surangular crest. These features also exclude Laosuchus naga from the other stem-amniote groups, i.e. from the Embolomeri (which do not present the features 1-4 and 7-10 mentioned above), the Gephyrostegidae (Gephyrostegus bohemicus (Carroll 1969) used in our analysis does not present the features 1, 5, 6, 9, 10 mentioned above), and the Seymouriamorpha (which do not present the features 1, 5, 6 mentioned above, based on Discosauriscus austriacus (Klembara 1997), Kotlassia prima (Bystrow 1944), Seymouria baylorensis (Laurin 1996)). For these reasons, we consider Laosuchus naga to be a chroniosuchian. As mentioned above, two families are present within the clade, the Chroniosuchidae and the Bystrowianidae: 
- As for the Bystrowianidae, Laosuchus naga shares with Bystrowiella schumanni an elongated jugal only, and with Bystrowiana permira a distinct transverse process with a descending flange and an elongated jugal only: these similarities, compared with the many differences observed between Laosuchus naga and these Bystrowianidae respectively (see description above), are therefore not sufficient to assign Laosuchus naga to this family.

- As for the Chroniosuchidae, Laosuchus naga does not show the preorbital fenestra typical of the family. It does share palatal characters with Chroniosaurus dongusensis and Chroniosuchus paradoxus (see comparison above), but as the palate is not known in Bystrowianidae, it is not possible to know if these characters are typical of Chroniosuchia or Chroniosuchidae. Moreover, Laosuchus naga does not fall close to a chroniosuchid in our phylogenetic analysis. For all these reasons mentioned above, we consider Laosuchus naga to be a Chroniosuchia, but of unknown familial affiliation.

\section{Chroniosuchian interrelationships}

The position of Chroniosuchia within early tetrapods varies according to the authors:

- In Schoch et al. (2010) and Buchwitz et al. (2012) (using a modified version of the matrix of Schoch et al. (2010)), Chroniosuchia have a relatively derived position close to the lepospondyl Asaphestera intermedia.

- In Clack \& Klembara (2009) and Witzmann \& Schoch (2017) (all using a modified version of the matrix of Ruta \& Clack, 2006), Chroniosuchia form a polytomy with Silvanerpeton miripedes, Embolomeri and another clade comprising Seymouriamorpha, Gephyrostegidae, Lepospondyli and the amniote Paleothyris acadiana. As the matrix of Ruta \& Clack (2006), used as starting point in these analyses, includes more characters and stem-tetrapod taxa than that of Schoch et al. (2010) (except for the number of chroniosuchian taxa), these results are believed to be more relevant concerning the interrelationships of Chroniosuchia. It is however the opposite for the intrarelationships of the chroniosuchians (see above).

Interestingly, all the analyses of mentioned above suggest similar relationships (i.e., Embolomeri, (Gephyrostegidae (Seymouriamorpha, Lepospondyli))), with only Chroniosuchia variably positioned among these taxa. Consequently, it is evident that these problematic chroniosuchians require further studies and phylogenetic analyses: one idea could be to integrate the best preserved chroniosuchian taxa in the exhaustive matrix of Ruta \& Clack (2006) - or a modified version of it - to better test their intra- and inter-relationships at the same time. But such an analysis would require first-hand examination of a large number of stemamniote taxa, and goes beyond the scope of this study. 


\section{Palaeobiogeographic implications (Fig. 11)}

Laosuchus naga is the first chroniosuchian from Laos. It was found in the Permo-Triassic Luang Prabang Basin, which has also yielded dicynodont material described by Battail (2009) and analysed in detail by Olivier et al. (submitted). No other vertebrates are known from this basin so far.

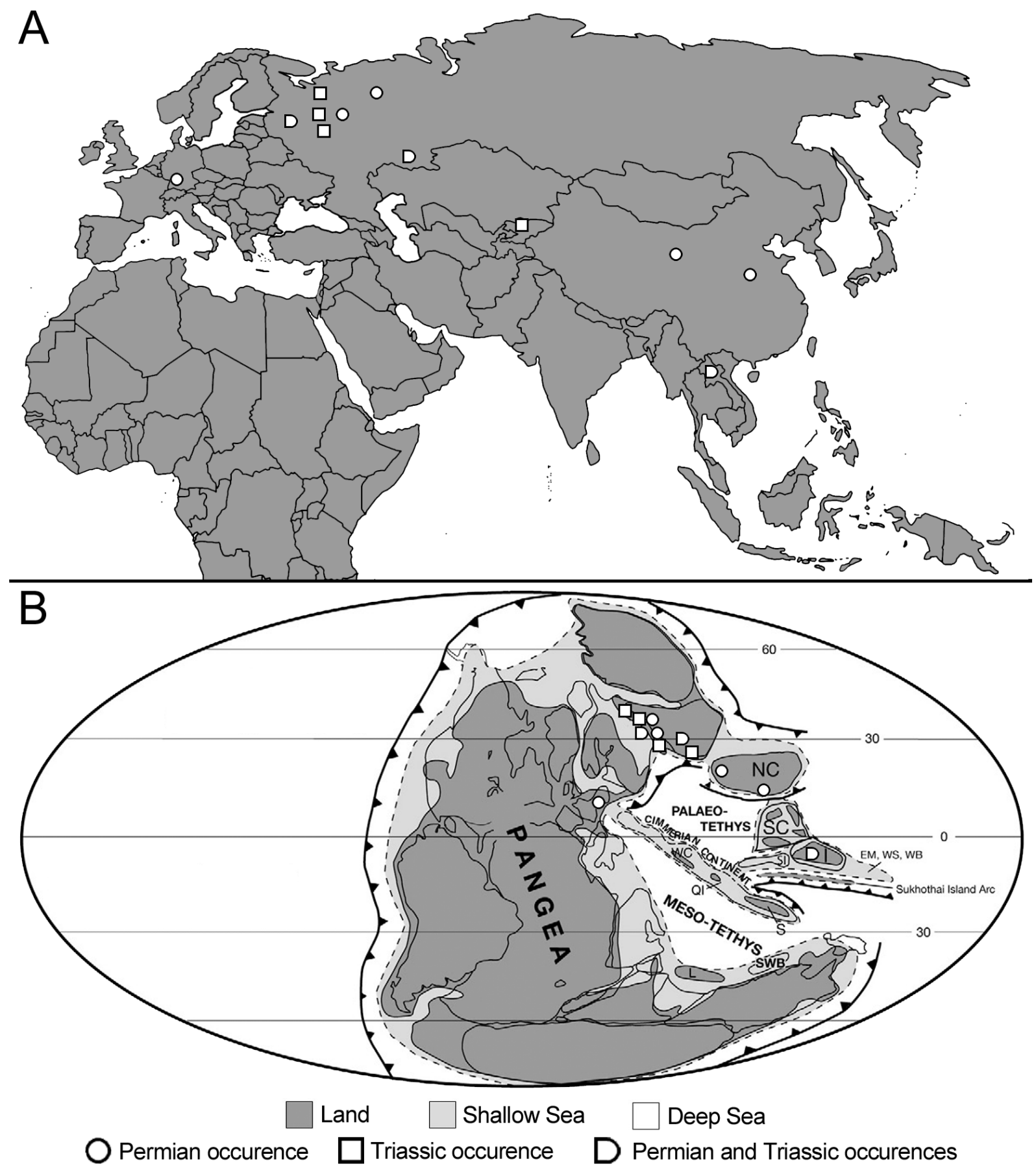

Figure 11. Stratigraphic and geographic distribution of chroniosuchian fossils. A. Presentday geographic map B. Late Permian palaeogeographic map (modified from Metcalfe 2011). 
As the holotypic specimen was found in-situ, in a volcaniclastic siltstone layer of the Luang Prabang Basin (see above), it is not geologically reworked. As such, the maximum age of Laosuchus naga is that of its host strata, which were radiometrically dated of $251.0 \pm 1.4 \mathrm{My}$ according to the $\mathrm{U}-\mathrm{Pb}$ dating of Rossignol et al. (2016) based on detrital zircons. This age estimate overlaps with the Permian-Triassic (PT) boundary according to most recent studies (Shen et al. 2011). The occurrence of a chroniosuchian in this part of the world and at this time brings interesting implications in term of palaeobiogeography and evolution.

Asia is composed of a mosaic of tectonic plates including the North China Block (hereafter NCB), the South China Block (SCB), and the Indochina Block (IB; where Laos is located). As these plates have very complex histories during the Permian and the Triassic (e.g. Metcalfe 2011), the reconstruction of Pangea remains highly debated concerning this part of the world. Two different palaeogeographic scenarios of eastern Pangea have been proposed for the PT interval: the first scenario suggests that the NCB, the SCB and the IB were at least partly separated by ocean(s) (e.g. Zhang et al. 2013), whereas the second scenario suggests that these blocks were connected like a peninsula linked to Laurussia (e.g. Buffetaut 1989, Metcalfe 2006, 2011; Vuong et al. 2013).

As mentioned above, chroniosuchian fossils are known from the middle Permian to Middle Triassic of Russia, middle to upper Permian of China, Middle Triassic of Germany and Middle/Upper Triassic of Kyrgyzstan (e.g. Novikov et al. 2000; Young 1979; Witzmann et al. 2008; Schoch et al. 2010, respectively). The new occurrence of the amphibious Laosuchus naga in nonmarine rocks therefore supports the second palaeogeographic scenario, as previously proposed by Buffetaut (1989). This scenario also fits with the discovery of dicynodont material (terrestrial species) in the same Purple Claystones Formation of Laos (Battail 2009; Olivier et al. submitted).

\section{Possible function(s) of the dermo-sensory and/or nutritive canals}

Two kinds of canals have been found in Laosuchus naga: simple canals in the skull roof (Fig.6A) and ramified canals in the premaxilla, maxilla and mandible (Fig. 6A, C).

The simple canals are interpreted as internalized sulci belonging to the lateral line system, considering their 1) location on the skull roof, 2) close proximity with the bone surface, and 3) shape. As in most modern fish, the lateral line system allows the animal to perceive displacements in surrounding water (i.e. a water flow). Similar canals have been found in other 
non-amniote tetrapods, with a similar function inferred (e.g. Ahlberg et al., 1994; Jarvik, 1996; Clack, 2002).

The ramified canals observed in Laosuchus naga are the first ones found in a fossil amphibian. As the structure differs from sulci and are deeper in the bone, they likely had a different function from the lateral line system. Their diameter and ramified structure are consistent with a vascular system, hence suggesting a blood irrigation function. As these ramifications are located at the tip of the snout and mandible, this possible irrigation may be associated with a sensory function. Similar canals, called "neurovascular canals", are also known in living species where they have various sensorial functions in addition to irrigation: mechanoreception in crocodiles and birds (Soares 2002; Leitch \& Catania 2012; Schneider et al. 2014), thermoreception in lizards and snakes (e.g. Seebacher \& Franklin 2005), electroreception in platypus (Gregory et al. 1987). In crocodiles, these canals are used when the head of the animal is half-emerged to detect surface waves (i.e., pressure waves) generated by prey moving in water which help with prey capture, especially in low-visibility conditions (e.g. turbid waters, crepuscule/night period) (Soares 2002; Leitch \& Catania 2012).

There is some evidence suggesting that mechanoreception is a plausible function for the canals via nervous structures associated to the significant blood irrigation. The numerous small conical and curved teeth indicate that Laosuchus naga was a predator. Moreover, the sediments that yielded Laosuchus naga suggest a fluviatile river environment (Bercovici et al. 2012) under a tropical, warm and wet climate (e.g. Fluteau et al. 2001; Bercovici et al. 2012). These characteristics suggest a similar ecology with living crocodiles, which also share morphological cranial convergences with Laosuchus naga (e.g. elevated skull table and orbits, long triangular snout, predator dentition). Hence, regarding morphological and ecological similarities, the ramified canals may have had the same additional function of mechanoreception. This possible function seems redundant with that of its internal sulci, but both systems (neurovascular and lateral line) are not sensitive to the same stimuli, both in nature (particle displacement versus pressure waves) and efficiency area (underwater versus water surface). Hence, the pressure waves system would have been complementary to the internal sulci.

\section{Surviving the Permian-Triassic crisis?}

Chroniosaurus dongusensis is one of the earliest chroniosuchians (Clack \& Klembara 2009) but not the most basal one, according to our phylogenetic analysis (Fig. 8). Additionally, the microsaur Asaphestera intermedia (from the Upper Carboniferous) was found as the sistertaxon to the chroniosuchian clade. This relationship suggests a long ghost lineage of the 
chroniosuchians, as suggested by Buchwitz et al. (2012). However, this clade is known to have survived the PT mass extinction (e.g. Novikov et al. 2000; Buchwitz et al. 2012). If Laosuchus naga can be confirmed as Triassic in age, its lineage must have also crossed the Permo-Triassic boundary. Even if some factors such as those involving palaeoclimates and/or palaeogeography can be put forward to explain these survival cases, it seems that more and more tetrapods survived the largest mass extinction of the Phanerozoic.

\section{Conclusion}

Laosuchus naga gen. et sp. nov., is described as the first chroniosuchian from Laos on the basis of a well-preserved skull and a left hemimandible found in natural articulation. The radiochronologic age of the sediments yielding the specimen gives a late Permian-Early Triassic age, which suggests that this new taxon may have survived the Permian-Triassic mass extinction. Laosuchus naga is represented by one of the best preserved chroniosuchian skulls. However, it remains of unknown familial relationships because the holotype does not preserve any postcranial elements. As a nonmarine tetrapod, Laosuchus naga also has important palaeobiogeographic implications: its occurrence on the Indochinese Block and its phylogenetic position suggest that the Indochinese Block was connected to the surrounding tectonic blocks during late Permian-Early Triassic times. Laosuchus naga was analysed by computed microtomography and is the first chroniosuchian for which the internal anatomy has been described. This 3D analysis revealed in particular new ramified canals inside the dentary, maxillae and premaxillae: they are interpreted as nutritive and/or dermo-sensory canals, probably linked with pressure receptors. Our phylogenetic analysis pointed out an important ghost lineage between Chroniosuchia and their close stem-amniote relatives. However, chroniosuchians remain a rare and poorly known clade: further studies will provide essential information to better understand the evolution of stem-amniotes.

Acknowledgements-We thank B. Battail, M. Véran, P. Richir (MNHN), R. Damiani (ex. BPI Johannesburg), J.-P. Porte (CERN), B. Khenthavong (Autorité Nationale pour la Science et la Technologie, Musée des Dinosaures, Savannaketh), B. Phanmongkhoune (Bureau de la Culture, Luang Prabang Province), S. Lorrain and M. Boulay (Cossima Productions) for field assistance, P. Richir (MNHN) for the extraction, R. Vacant (CR2P CNRS) for the preparation, 
P. Loubry (CR2P CNRS) and L. Caze (MNHN) for the photos, S. Vongphamany (Department of Patrimony, Museums and Archeology, Vientiane) for field authorization and exportation permit. We thank the Governor of the Luang Prabang Province for assistance, J.-P. Cuomo and F. Engelmann (Luang Prabang) for their support. NGS grant 7655-04 (to JSS), and a MESR Doctoral grant (to TA) supported this research. We thank M. Buchwitz and an anonymous reviewer for their useful comments.

\section{References}

Ahlberg, P. E., Luksevics, E. \& Lebedev, O. 1994. The first tetrapod finds from the Devonian (Upper Famennian) of Latvia. Philosophical Transactions of the Royal Society of London B: Biological Sciences, 343, 303-328.

Arbez, T., Dahoumane, A. \& Steyer, J. S. 2017. Exceptional endocranium and middle ear of Stanocephalosaurus (Temnospondyli: Capitosauria) from the Triassic of Algeria revealed by micro-CT scan, with new functional interpretations of the hearing system. Zoological Journal of the Linnean Society, 180, 910-929.

Battail, B. 2009. Late Permian dicynodont fauna from Laos. Geological Society of London Special Publication, 315, 33-40.

Battail, B., Dejax, J., Richir, P., Taquet, P. \& Veran, M. 1995. New data on the continental Upper Permian in the area of Luang-Prabang, Laos. Journal of Geology, Series B, 5, 11-15.

Benton, M. J. 2004. Vertebrate Paleontology, 3rd ed. Blackwell Science, Oxford, 472 pp.

Benton, M. J. \& Twitchett, R. J. 2003. How to kill (almost) all life: the end-Permian extinction event. Trends in Ecology \& Evolution, 18, 358-365

Bercovici, A., Bourquin, S., Broutin, J., Steyer J.-S, Battail, B., Véran, M., Vacant, R., Khenthavong, B. \&Vongphamany, S. 2012. Permian continental paleoenvironments in southeastern Asia: new insights from the Luang Prabang Basin (Laos). Journal of Asian Earth Sciences, 60, 197-211. 
Brayard, A., Bucher, H., Escarguel, G., Fluteau, F., Bourquin, S. \& Galfetti, T. 2006. The Early Triassic ammonoid recovery: paleoclimatic significance of diversity gradients. Palaeogeography, Palaeoclimatology, Palaeoecology, 239, 374-395.

Buchwitz, M., Witzmann, F., Voigt, S. \& Golubev, V. 2011. Osteoderm microstructure indicates the presence of a crocodylian-like trunk bracing system in a group of armoured basal tetrapods. Acta Zoologica, 93, 260-280.

Buchwitz, M., Foth, C., Kogan, I. \&Voigt, S. 2012. On the use of osteoderm features in a phylogenetic approach on the internal relationships of the Chroniosuchia (Tetrapoda: Reptiliomorpha). Palaeontology, 55, 623-640.

Buffetaut, E. 1989. The contribution of vertebrate palaeontology to the geodynamic history of South East Asia. Pp. 645-653 in A. M. C. Sengõr (eds) Tectonic evolution of the Tethyan region. Kluwer Academic Publishers, Dordrecht.

Bystrow, A. P. 1944. Kotlassia prima Amalitzky. Geological Society of America Bulletin, 55, 379-416.

Bystrow, A. P. \& Efremov, J. A. 1940. Benthosuchus sushkini - a labyrinthodont from the Eotriassic of Sharzhenga River. Trudy Paleozoologicheskogo Instituta Akademii Nauk SSSR, 10, 1-152 [in Russian].

Carroll, R. L. 1969. Problems of the origin of reptiles. Biological Reviews, 44, 393-431.

Carroll, R. L. 1970. The ancestry of reptiles. Philosophical Transactions of the Royal Society $B, 257,267-308$.

Carroll, R. L. \& Gaskill, P. 1978. The order Microsauria. Memoirs of the American Philosophical Society, 126, 1-211.

Chen, Z. Q. \& Benton, M. J. 2012. The timing and pattern of biotic recovery following the end-Permian mass extinction. Nature Geoscience, 5, 375-383.

Clack, J. A. 2002. The dermal skull roof of Acanthostega gunnari an early tetrapod from the Late Devonian. Transactions of the Royal Society of Edinburgh: Earth Sciences, 93, 17-33. 
Clack, J. A. \& Holmes, R. 1988. The braincase of the anthracosaur Archeria crassidisca with comments on the interrelationships of primitive tetrapods. Palaeontology, 31, 85-107.

Clack, J.A. \& Klembara, J. 2009. An articulated specimen of Chroniosaurus dongusensis, and the morphology and relationships of chroniosuchids. Special Papers in Palaeontology, 81, 15-42.

Counillon, J. B. H. 1896. Documents pouvant servir à l'étude géologique des environs de Luang Prabang (Cochinchine). Comptes Rendus de l'Académie des Sciences, 123, 1330-1333 [in French].

Dutuit, J. M. 1976. Introduction à l'étude paléontologique du Trias continental marocain. Description des premiers Stégocephales recueillis dans le Couloir d'Argana (Atlas Occidental). Mémoires du Muséum National d'Histoire Naturelle, Série C, Sciences de la Terre, 36, 1-253 [in French].

Fluteau, F., Besse, J., Broutin, J. \& Ramstein, G. 2001. The Late Permian climate. What can be inferred from climate modelling concerning Pangea scenarios and Hercynian range altitude? Palaeogeography, Palaeoclimatology, Palaeoecology, 167, 39-71.

Golubev, V. K. 1998. Revision of the Late Permian chroniosuchians (Amphibia: Anthracosauria) from Eastern Europe. Paleontological Journal, 32, 390-401.

Goodrich. E. S. 1930. Studies on the structure and development of vertebrates. Macmillan, London, 837 pp.

Gregory, J. E., Iggo, A., McIntyre, A. K., \& Proske, U. 1987. Electroreceptors in the platypus. Nature, 326, 386-387.

Hartmann-Weinberg, A. P. 1935. The dermal ossifications of the Russian seymouriamorphs. Trudy Paleozoologicheskogo Instituta Akademii Nauk SSSR, 4, 53-67 [in Russian].

Holmes, R. 1984. The Carboniferous amphibian Proterogyrinus scheelei Romer, and the early evolution of tetrapods. Philosophical Transactions of the Royal Society of London B: Biological Sciences, 306, 431-524. 
Holmes, R. 1989. The skull and axial skeleton of the Lower Permian anthracosauroid amphibian Archeria crassidisca Cope. Palaeontographica A, 207, 161-206.

Ivakhnenko, M. F. \& Tverdokhlebova, G. I. 1980. Systematics, morphology, and stratigraphic significance of the upper permian chroniosuchians from the East of the European part of the USSR. Izdatelstvo Saratovskogo Universiteta, Saratov, 69 pp [in Russian].

Jarvik, E. 1996. The Devonian tetrapod Ichthyostega. Fossils and Strata, 40, 1-206.

Jiang, S., Ji, S. \& Mo, J. 2017. First record of Bystrowianid Chroniosuchians (Amphibia: Anthracosauromorpha) from the Middle Permian of China. Acta Geologica Sinica (English Edition), 91, 1523-1529

Klembara, J. 1997. The cranial anatomy of Discosauricsus Kuhn, a seymouriamorph tetrapod from the Lower Permian of the Boskovice Furrow (Czech Republic). Philosophical Transactions of the Royal Society of London B: Biological Sciences, 352, 257-302.

Klembara, J. 2009. New cranial and dental features of Discosauriscus austriacus (Seymouriamorpha, Discosauriscidae) and the ontogenetic conditions of Discosauriscus. Special Papers in Palaeontology, 81, 61-69.

Klembara, J., Clack, J. A. \& Čerňanský, A. 2010. The anatomy of palate of Chroniosaurus dongusensis (Chroniosuchia, Chroniosuchidae) from the Upper Permian of Russia. Palaeontology, 53, 1147-1153.

Laurin, M. 1996. A redescription of the cranial anatomy of Seymouria baylorensis, the best known seymouriamorph (Vertebrata: Seymouriamorpha). Paleobios, 17, 1-16

Leitch, D. B. \& Catania, K. C. 2012. Structure, innervation and response properties of integumentary sensory organs in crocodilians. Journal of Experimental Biology, 215, 42174230.

Li, J. \& Cheng, Z. 1999. New anthracosaur and temnospondyl amphibians from Gansu, China. Vertebrata PalAsiatica, 37, 234-247 [in Chinese]. 
Liu, J. \& Abdala, F. 2017. Therocephalian (Therapsida) and chroniosuchian (Reptiliomorpha) from the Permo-Triassic transitional Guodikeng Formation of the Dalongkou Section, Jimsar, Xinjiang, China. Vertebrata PalAsiatica, 55, 24-40.

Metcalfe, I. 2006. Palaeozoic and Mesozoic tectonic evolution and palaeogeography of East Asian crustal fragments: the Korean Peninsula in context. Gondwana Research, 9, 24-46.

Metcalfe, I. 2011. Tectonic framework and Phanerozoic evolution of Sundaland. Gondwana Research, 19, 3-21.

Novikov, I. V., Shishkin, M. A. \& Golubev, K. 2000. Permian and Triassic anthracosaurs from Eastern Europe. In: Benton M. J., Shishkin M. A., Unwin D. M., Kurochkin E. M., eds. The age of dinosaurs in Russia and Mongolia. Cambridge: Cambridge University Press, 6070.

Olivier, C., Battail, B., Bourquin, S., Rossignol, C., Steyer, J.-S. \& Nour-Eddine, Jalil. Submitted. New dicynodonts (Anomodontia, Therapsida) from the Early Triassic of Laos illustrate the tetrapod recovery after the Permian-Triassic extinction.

Panchen, A. L. 1964. The cranial anatomy of two Coal Measure anthracosaurs. Philosophical Transactions of the Royal Society London B, 247, 593-636.

Panchen, A. L. 1972. The skull and skeleton of Eogyrinus attheyi Watson (Amphibia: Labyrinthodontia). Philosophical Transactions of the Royal Society London B, 263, 279-326.

Panchen, A. L. 1977. On Anthracosaurus russelli Huxley (Amphibia: Labyrinthodontia) and the family Anthracosauridae. Philosophical Transactions of the Royal Society B: Biological Sciences, 279, 447-512.

Romer, A. S. 1946. The primitive reptile Limnoscelis restudied. American Journal of Science, 244, 149-188.

Romer, A. S. \& Witter, R. V. 1942. Edops, a primitive rhachitomous amphibian from the Texas Red Beds. Journal of Geology, 50, 925-960.

Rossignol, C., Bourquin, S., Poujol, M., Hallot, E., Dabard, M. P. \& Nalpas, T. 2016. The volcaniclastic series from the Luang Prabang Basin, Laos: A witness of a triassic magmatic arc? Journal of Asian Earth Sciences, 120, 159-183. 
Säve-Söderbergh, G. 1934. Some points of view concerning the evolution of the vertebrates and the classification of this group. Arkiv för Zoologi, 26A, 1-20.

Sawin, H. J. 1941. The cranial anatomy of Eryops megacephalus. Bulletin of the Museum of Comparative Zoology Harvard, 89, 407-463.

Schoch, R. R., Voigt, S. \& Buchwitz, M. 2010. A chroniosuchid from the Triassic of Kyrgyzstan and analysis of chroniosuchian relationships. Zoological Journal of the Linnean Society, 160, 515-530.

Schneider, E. R., Mastrotto, M., Laursen, W. J., Schulz, V. P., Goodman, J. B., Funk, O. H., Gallagher, P. G., Gracheva, E. O. \& Bagriantsev, S. N. 2014. Neuronal mechanism for acute mechanosensitivity in tactile-foraging waterfowl. Proceedings of the National Academy of Sciences, 111, 14941-14946.

Seebacher, F. \& Franklin, C. E. 2005. Physiological mechanisms of thermoregulation in reptiles: a review. Journal of Comparative Physiology B, 175, 533-541.

Shen, S. Z., Crowley, J. L., Wang, Y., Bowring, S. A., Erwin, D. H., Sadler, P. M., Cao, C.Q., Rothman, D.H., Henderson, C.M., Ramezani, J., Zhang, H., Shen, Y., Wang, X.D., Wang, W., Mu, L., Li, W.Z., Tang, Y.G., Liu, X.L., Liu, L.J., Zeng, Y., Jiang, Y.F. \& Jin, Y.G. 2011. Calibrating the end-Permian mass extinction. Science, 334,1367-1372.

Shishkin, M. A., Novikov, I. V. \& Gubin, Y. M. 2000. Permian and Triassic anthracosaurs from Eastern Europe. Pp. 60-70 in Benton M. J., Shishkin M. A., Unwin D. M., \& Kurochkin E. N. (eds) The Age of Dinosaurs in Russia and Mongolia. Cambridge University Press, Cambridge.

Shishkin, M. A., Sennikov, A. G., Novikov, I. V. \& Ilyina, N. V. 2006. Differentiation of tetrapod communities and some aspects of biotic events in the Early Triassic of Eastern Europe. Paleontological Journal, 40, 1-10.

Smithson, T. R. 1985. The morphology and relationships of the Carboniferous amphibian Eoherpeton watsoni Panchen. Zoological Journal of the Linnean Society, 85, 317-410.

Soares, D. 2002. Neurology: an ancient sensory organ in crocodilians. Nature, 417, 241-242. 
Steyer, J.-S. 2000. Ontogeny and phylogeny in temnospondyls: a new method of analysis. Zoological journal of the Linnean Society, 130, 449-467.

Steyer, J.-S. 2003. A revision of the early Triassic "capitosaurs" (Stegocephali, Stereospondyli) from Madagascar, with remarks on their comparative ontogeny. Journal of Vertebrate Paleontology, 23, 544-555.

Steyer, J.-S. 2009. The geological and palaeontological exploration of Laos; following in the footsteps of J. B. H. Counillon and A. Pavie. Geological Society, London, Special Publications, 315, 25-32.

Swofford, D. L. 2003. PAUP*, Phylogenetic analysis using parsimony (*and other methods). Version 4. Sunderland: Sinauer Associates.

Tatarinov, L. P. 1972. Seymouriamorphen aus der Fauna der UdSSR. Pp. 70-80 in: Kuhn O (eds) Encyclopedia of Paleoherpetology, Volume 5B. Gustav Fischer, Stuttgart.

Tverdokhlebov, V. P., Tverdokhlebova, G. I., Minikh, A. V., Surkov, M. V. \& Benton, M. J. 2005. Upper Permian vertebrates and their sedimentological context in the South Urals, Russia. Earth-Science Reviews, 69, 27-77.

Vjushkov, B, P. 1957a. New peculiar animals from strata of the Tatarian Series in the European part of the USSR. Doklady Akademiya Nauk SSSR, 113, 183-186 [in Russian].

Vjushkov, B. P. 1957b. New kotlassiomorphs from the Tatarian Series in the European part of the USSR. Pp. 89-107 in: Vjuschkov B. P. (eds) Upper Permian cotylosaurs and batrachosaurs from the SSSR. Nauka, Moscow [in Russian].

Vuong, N. V., Hansen, B. T., Wemmer, K., Lepvrier, C., Tích, V. V., \& Thắng, T. T. 2013. $\mathrm{U} / \mathrm{Pb}$ and $\mathrm{Sm} / \mathrm{Nd}$ dating on ophiolitic rocks of the Song Ma suture zone (northern Vietnam): evidence for upper paleozoic paleotethyan lithospheric remnants. Journal of Geodynamics, 69, 140-147.

Witzmann, F., Schoch, R. R. \& Maisch, M. W. 2008. A relic basal tetrapod from the Middle Triassic of Germany. Naturwissenschaften, 95, 67-72.

Witzmann, F. \& Schoch, R. R. 2017. Skull and postcranium of the bystrowianid Bystrowiella schumanni from the Middle Triassic of Germany, and the position of 
chroniosuchians within Tetrapoda. Journal of Systematic Palaeontology, DOI:

10.1080/14772019.2017.1336579

Young, C. C. 1979. A new Late Permian fauna from Jiyuan, Honan. Vertebrata Palasiatica, 17, 99-113. 